\title{
Analysis of alternative frequency control schemes for increasing renewable energy penetration in El Hierro Island power system
}

\author{
José Ignacio Sarasúa, Guillermo Martínez-Lucas, Marcos Lafoz
}

\author{
Keywords: \\ Frequency control \\ Isolated power system \\ Wind energy penetration \\ Flywheels \\ Variable speed pumps
}

\begin{abstract}
A B S T R A C T
El Hierro, island declared as a biosphere reserve by the UNESCO in 2000, aims to become self-sufficient in energy and $100 \%$ free of greenhouse gas emissions. This isolated power system consists of diesel units and a hybrid Wind- Pump Storage Hydropower Plant (W-PSHP), equipped with Variable Speed Wind Turbines (VSWTs), Pelton turbines and a pump station with both fixed- and variable-speed pumps. During last years the annual average renewable energy participation is increasing, especially due to the improvements in the frequency control strategies in PSHP including the operation in short circuit mode. This performance involves an important reduction of the system efficiency but allows PSHP to regulate frequency deviations when available wind power is higher than power demand and the Diesel units are disabled. In this paper different alternative frequency control schemes are proposed so that Pelton units support to the frequency control can be substituted, avoiding energy losses owing to short-circuit operation. This way renewable energy participation would be increased. The control schemes are developed using pumping station regulation capacity, the proper kinetic energy of the VSWTs rotors and a new Flywheel Energy Storage System connected to the grid by means of power electronics. Nine different control cases have been presented, including hydraulic short circuit operating mode. Different simulations have been carried out and they confirm that proposed control schemes fulfil the initial research objectives and enable to improve the global energy efficiency of the system.
\end{abstract}

1.

\section{Introduction}

Increasing renewable energy participation in isolated power systems

is a great challenge that has been constantly faced during last decades. Reducing fossil fuels involves an obvious environmental benefit but in isolated power systems economic advantages, due to reduction of combustible transport costs, are relevant too. One of the main facts that limits renewable energy penetration in these systems is the frequency control difficulties ow ing to th e re duction of sy stem in ertia an $d$ the power supplied variability, both inherent to the renewable sources [1].

As it is reported in [2] load shedding is a regular but non-desirable practice in isolated power systems with high penetration of non-dispatchable renewable energy sources. A drastic solution for avoiding this situation has been adopted in Martinique and Reunion islands where Government has limited the penetration of renewable sources to $30 \%$ due to serious problems of frequency deviations [3]. In this sense specific grid codes for island power systems have been d eveloped [4].
From technical point of view different $s$ olutions $h$ ave been adopted in order to facilitate increase of renewable penetration. Short and long term energy storage systems is probably the most common option. Introducing batteries [5] or flywheels [6 -8] in is olated s y stems has been used to mitigate fast variations of the power supplied by wind turbines; Pump Storage Hydropower Plants (PSHPs) are very common to be installed for storing renewable energy excesses and supplying this energy when the renewable source, wind or sun, is not available [9].

It is well known that PSHPs contribute satisfactorily to frequency regulation in turbine operation mode as well as starting and stopping units in pump operation mode [10]. However, thanks to advances in power electronics, PSHPs equipped with variable-speed units can currently contribute continuously to frequency regulation in both operating modes [11]. In Ref. [12] an isolated power system including a wind farm, a thermal power plant and a variable speed PSHP, was modelled. Simulation results confirmed that $v$ ariable s peed $u$ nits operating in pumping mode reduce frequency deviations caused by wind 


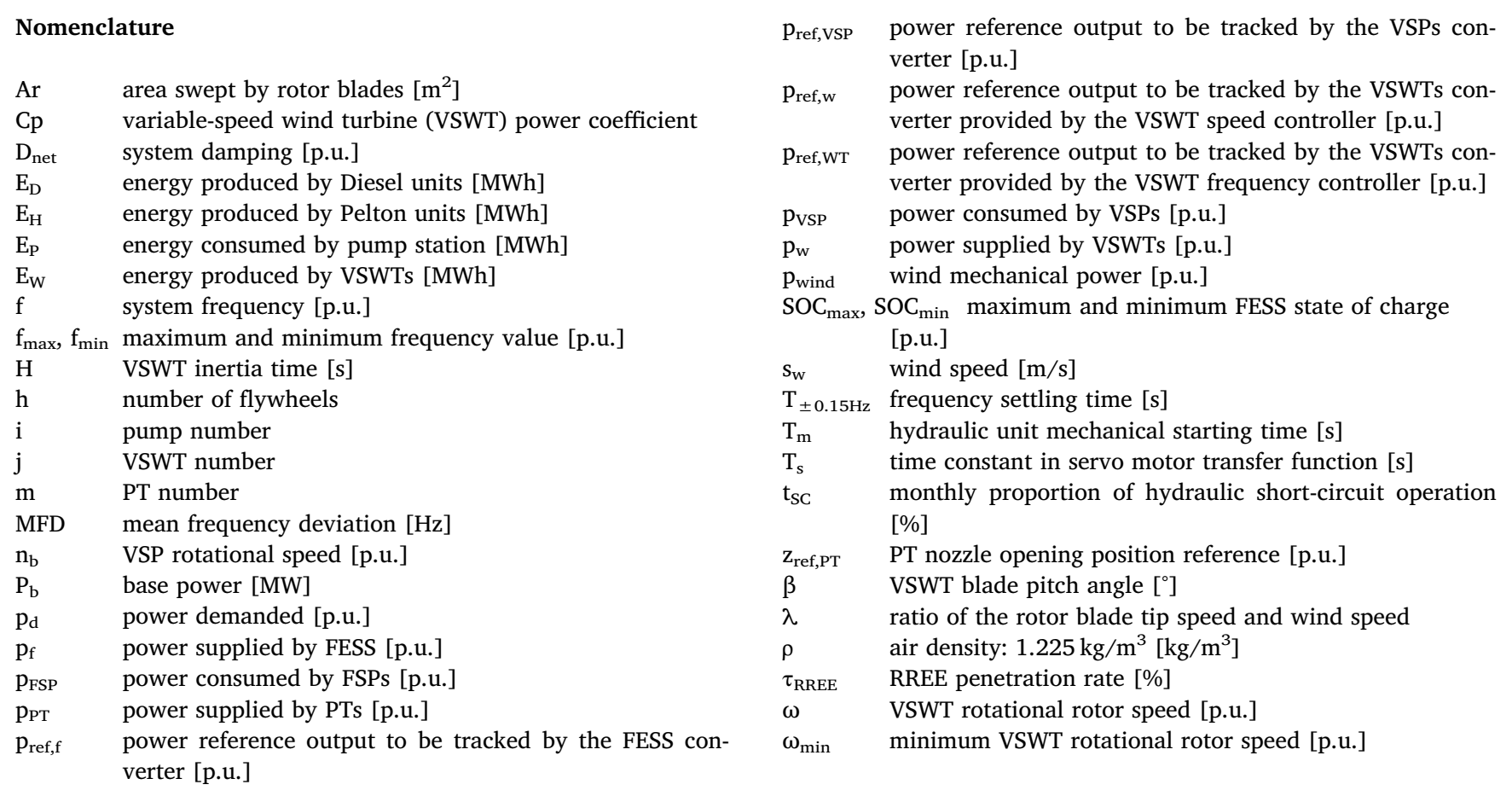

speed fluctuations. The same methodology was followed by [13] modelling the main components of the power system on the Faroe Islands, including a diesel group, a conventional hydropower plant, a wind farm and a PSHP. Simulation results confirmed that variable speed units in pumping mode can compensate fluctuations in the power generated by the wind farm. Authors in [14] presented a PSHP control strategy combining variable-speed-driven pumps and fixed-speeddriven pumps. Frequency regulation is provided by a dual controller involving a continuous speed regulator for the Variable Speed Pumps (VSPs) and a discrete controller for the Fixed Speed Pumps (FSPs).

Normally, non-dispatchable renewable energy sources are connected to the system by a stage of power converters, further reduces rotating inertia by substituting conventional generators. In these cases inertia could be emulated within the converters' control scheme. The kinetic inertia stored in the rotational masses of the VSWTs can be injected into the net, reducing frequency deviation during first seconds after a disturbance [15]. This practise does not involve a representative loss or energy [16].

El Hierro Island belongs to the Canary archipelago. Historically, diesel generators were the unique power source. However in June 2014 a hybrid wind pumped-storage hydropower plant (W-PSHP), Gorona del Viento, was committed to reduce fossil fuels dependence. Long term island objective is to become entirely free from carbon dioxide emissions. In these years renewable energy participation has been increasing. For example 2018 July the percentage of energy from renewable source was $95.4 \%$ [17] and during 18 consecutive days in 2018 January-February the energy consumed in the island was renewable [18]. This achievement has been reached by exploiting the maximum wind potential and introducing alternative control schemes as the hydraulic short circuit operation in the PSHP [19]. In this way, when the wind power is higher than power demand, pumps consume energy excesses and turbines are needed to do frequency regulation. The main drawback are the important efficiency losses inherent in its frequency control strategy. During last year short circuit operation control scheme was adopted during nearly $25 \%$ of time so the benefits of improving the efficiency without decreasing the renewable energy participation seem to be attractive.

In this paper different alternative frequency control schemes are proposed so that Pelton Turbines (PTs) contribution to the frequency control can be substituted, avoiding energy losses owing to short-circuit operation. This way renewable energy participation would be increased. The control schemes are developed using (i) pumping station regulation capacity (Energies), (ii) kinetic energy stored in the Variable Speed Wind Turbines (VSWTs) [20] rotors and (iii) a new Flywheel Energy Storage System (FESS) [8] connected to the grid through power electronics. Eight different control cases have been presented resulting of the combination of these control approaches. Also, hydraulic short circuit operation mode has been considered, as a base case, to compare the results from the new control schemes. A dynamic model has been developed in Matlab Simulink. The model includes the power system, the pump station, the hydropower plant, the VSWTs and the FESS and reproduces the frequency deviation by means of an aggregate inertial model. Therefore, the main contribution of this paper consist in comparing and valuing, by means of representative simulations, from the dynamic and energy points of view, proposed control schemes with the current operation mode when the wind power is high.

The paper is organised as follows. In Section 2, both the hybrid wind-hydro power plant and El Hierro power system are presented. The non-linear dynamic model developed in Matlab Simulink is described in Section 3. In Section 4, FESS, VSWTs, PTs and pump station controllers are described. In Section 5, some realistic simulations to support the proposed control strategies are presented. Finally, the main conclusions of this study are outlined.

\section{Hybrid wind-hydro power plant and power system description}

El Hierro is an island belonging to the Canary Islands archipelago, which was declared as a biosphere reserve by the UNESCO in 2000. The 


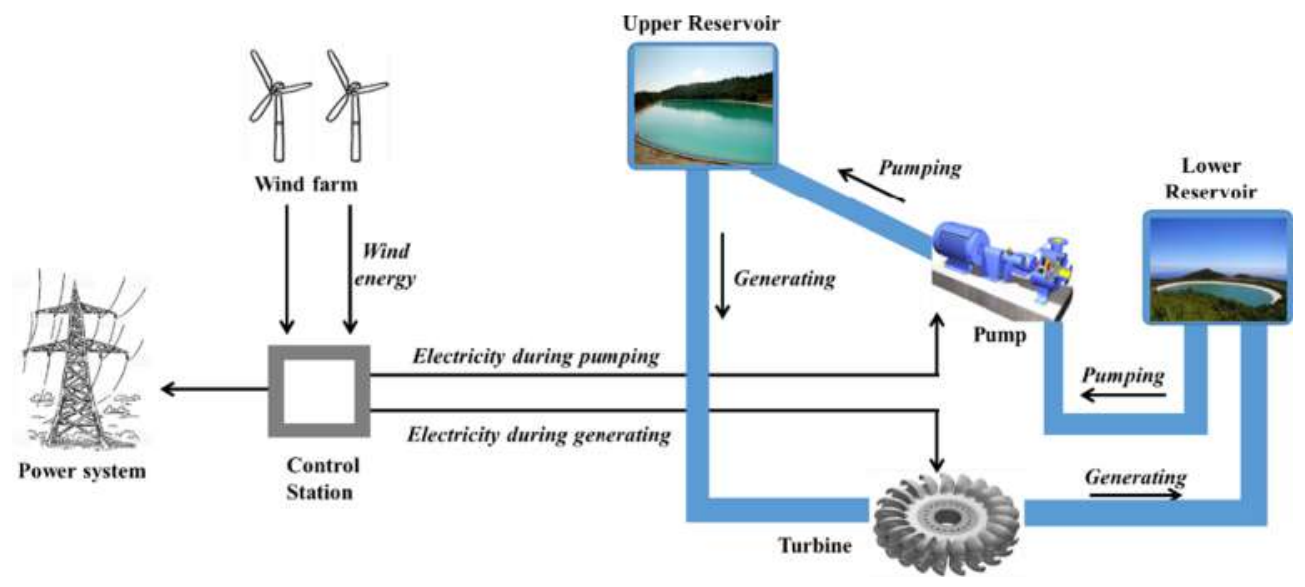

Fig. 1. Gorona del Viento Wind-Hydro power plant.

island aims to become self-sufficient in energy and $100 \%$ free of greenhouse gas emissions [21]. The electrical capacity of the island is 37.8 MW, mainly distributed by diesel generators of $15 \mathrm{MW}$ and a WPSHP (Gorona del Viento) at rated power of 22.8 MW; 11.5 MW comes from five ENERCON E-70 VSWTs. The W-PSHP is equipped with $4 \times 2.8$ MW Pelton turbines, $6 \times 0.5$ MW FSPs and $2 \times 1.5$ MW VSPs. Information provided by the Spanish Transmission System Operator (TSO) [17] shows that the maximum peaks demand in 2018 were 7.7 MW, whereas the minimum was 2.1 MW. The higher wind power penetration was $11.1 \mathrm{MW}$. Fig. 1 shows the simplified scheme of the WPSHP describing the water and energy flow according to the operation mode of the turbines and the pumps. This hydraulic configuration allows hydraulic short-circuit operation which consists on maintaining the pumps enable while turbines are generating at the same time. Therefore PSHP can contribute to the frequency regulation when the net power generation is negative (energy consumed by pumps is higher than energy produced by turbines). This performance involves an important reduction of the system efficiency but allows Gorona del Viento to regulate frequency deviations without the Diesel units contribution when wind power is higher than power demand [19].

Table 1 lists the El Hierro power system energy mix during 2018 grouped by months. For information about years 2016 and 2017 see [22]. The average renewable energy penetration rate rounds $50 \%$, highlighting a great variance between the maximum (more than $95 \%$ in July) and the minimum (less than $25 \%$ in October). The annual average renewable energy penetration has specially increased during last years ( $40.6 \%$ in 2016, $46.27 \%$ in 2017 and $56.6 \%$ in 2018 [17,22]). This increment has mainly achieved due to the improvements in the frequency control strategies implanted in PSHP turbine groups [19]. The low values of the quotient between the total amount of energy generated by turbines and the total amount of energy consumed by pumps is due to the number of hours that the PSHP is operating in hydraulic short-circuit mode. In PSHPs operating in a conventional way this ratio matches the round-trip efficiency and usually achieves a $78 \%$ corresponding to the maximum operating point [23]. In fact, the monthly time percentage operating in short-circuit mode is also listed in Table 1, reaching more than the $75 \%$ in July.

Therefore, short-circuit operation is the strategy currently adopted by the PSHP operator when there is high wind power production. In this operation mode, frequency control is carried out only by PTs controllers. In this paper different frequency control schemes are proposed so that Pelton units contribution to the frequency control can be substituted when the wind power penetration is high, avoiding energy losses owing to short-circuit operation. These control schemes are developed using basically three elements. First one consists in taking advantage of the pumping station following the work developed by [14]. Second one is based on using the kinetic energy stored in the VSWTs rotors to reduce frequency deviations. The last one relies on introducing a new FESS in the power system. Nowadays, there are not any FESS in the island but authors in [8] have studied different issues about installing a new FESS in El Hierro analysing different FESS sizes and controllers. Therefore, authors consider very interesting to introduce the regulation capacity of a feasible FESS at a rated power of $150 \mathrm{~kW}$ and $300 \mathrm{~kW}$ in order to evaluate the benefits of installing it next to the other mentioned elements. As all control schemes involve frequency converters the four generators driven by the Pelton turbines are needed to operate as synchronous condensers and not in no-flow mode [24]. Therefore, they provide voltage regulation and inertia.

Fig. 2 shows the simplified one line diagram of El Hierro power system in this scenario.

Table 1

Real data energy production (and consumption) in El Hierro power system during 2018.

\begin{tabular}{|c|c|c|c|c|c|c|c|c|c|c|c|c|c|}
\hline & \multicolumn{12}{|l|}{ Month } & \multirow[t]{2}{*}{ Year } \\
\hline & $1 / 18$ & $2 / 18$ & $3 / 18$ & $4 / 18$ & $5 / 18$ & $6 / 18$ & $7 / 18$ & $8 / 18$ & $9 / 18$ & $10 / 18$ & $11 / 18$ & $12 / 18$ & \\
\hline$E_{D}$ & 1235.7 & 1391.7 & 1762.0 & 1003.0 & 1501.1 & 1371.8 & 190.1 & 1254.5 & 1760.3 & 2947.2 & 2327.1 & 2448.9 & 19193.3 \\
\hline$E_{W}$ & 3501.3 & 2481.5 & 2551.4 & 3371.3 & 3026.4 & 3236.2 & 5480.5 & 4160.5 & 3063.6 & 1285.6 & 1375.5 & 1392.8 & 34926.6 \\
\hline$E_{H}$ & 242.4 & 133.5 & 199.5 & 241.2 & 119.3 & 235.2 & 318.0 & 197.7 & 250.3 & 108.5 & 109.2 & 147.5 & 2302.1 \\
\hline$E_{P}$ & 1378.7 & 778.4 & 1052.1 & 1249.8 & 1018.0 & 1008.8 & 1897.0 & 1337.4 & 1010.7 & 426.8 & 487.4 & 541.4 & 12186.6 \\
\hline$E_{H} / E_{P}$ & $17,6 \%$ & $17,1 \%$ & $19,0 \%$ & $19,3 \%$ & $11,7 \%$ & $23,3 \%$ & $16,8 \%$ & $14,8 \%$ & $24,8 \%$ & $25,4 \%$ & $22,4 \%$ & $27.2 \%$ & $19.9 \%$ \\
\hline$t_{S C}$ & $32.1 \%$ & $34.3 \%$ & $27.3 \%$ & $26.8 \%$ & $14.5 \%$ & $24.0 \%$ & $75.7 \%$ & $41.2 \%$ & $11.1 \%$ & $0.60 \%$ & $1.16 \%$ & $1.10 \%$ & $24.17 \%$ \\
\hline$\tau_{R R E E}$ & $65,7 \%$ & $56,9 \%$ & $49,1 \%$ & $70,2 \%$ & $58,6 \%$ & $64,2 \%$ & $95,4 \%$ & $70,7 \%$ & $56,7 \%$ & $24,7 \%$ & $30,0 \%$ & $29.0 \%$ & $65.61 \%$ \\
\hline
\end{tabular}




\section{Hybrid wind-hydro power plant model description}

A dynamic model has been developed in order to check the viability of increasing wind power penetration avoiding energy from diesel groups. The model is carried out in Matlab Simulink. The main components of the model are the power system, the pump station, VSWTs and FESS. The hydropower plant only provides inertia so this feature is included in the power system model. The size of the power system is limited so power lines do not seriously affect to the frequency system and their influence is neglected.

\subsection{Power system}

According to the power system size, an aggregated inertial model [25] has been used for reproducing system frequency deviations. This approximation has been successfully used in [26] in a bigger power system as the Irish one. The imbalance between power generated by wind turbines $p_{w}$ and Pelton turbines $p_{P T}$ (only in hydraulic short circuit operation mode) and the power consumed by the pump station, $p_{F S P}$ and $p_{V S P}$, and consumer loads $p_{d}$ produces frequency variations according to expression (1). FESS may provide $\left(p_{f}>0\right)$ or absorb $\left(p_{f}<0\right)$ power from the system whenever it is necessary. Consumer loads sensitivity to frequency variations is includes by means of $D_{\text {net }}$ term.

Apart from FSPs, all the rotating machines included in expression (1) are connected to the grid through frequency converters so they do not contribute to the system inertia. This lack is solved by hydroelectric groups which are connected as synchronous condensers. Therefore, system inertia, $T_{m}$, corresponds to the mechanical starting time of the four Pelton units.

$$
\begin{aligned}
f \frac{d f}{d t} & \\
= & \frac{1}{T_{m}}\left(\sum_{j=1}^{5} p_{w, j}+\sum_{m=1}^{4} p_{P T, m}+\sum_{h} p_{f, h}-\sum_{i=2}^{7} p_{F S P, i}-\right. \\
& \left.\sum_{i=1,8} p_{V S P, i}-p_{d}-D_{n e t} \cdot \Delta f\right)
\end{aligned}
$$

\subsection{Pump station}

As it is stated below, frequency control support may be delivered by the pump station varying the power consumed by VSPs and the number of FSPs connected to the grid. Therefore, a detailed model of the pumps and the hydraulic circuit is needed. This model should include the influence of hydraulic and mechanical phenomena in the pump station dynamic response. This model was explained in detail in [14] so the main characteristics are summarized in this section.

\subsubsection{Conduits}

The hydraulic circuit between the lower reservoir and the head pond is composed by eight pipes that joint the lower reservoir with each pump, eight pipes connecting the pumps with the manifold and the common penstock between the manifold and the head pond. The length of the first pipes from the lower reservoir is really short so their contribution to the dynamic of the circuit is neglected. All the pipes from the pumps are supposed to joint in the same point in the manifold.

The sum of the flows of each pipe determines the total flow in the upstream edge of the penstock. Penstock length is long enough to include elastic phenomena for modelling its dynamic response. In order to take into account water and conduit elasticity, a lumped parameters approach has been used [12].

\subsubsection{Hydraulic and electric machines}

Assuming that the internal dynamic in the hydraulic machines is neglected [27], quadratic equations express the relation between net head, flow, rotational speed and mechanical power of the pumps. The hydraulic similarity has been used to deduce the net head and the mechanical power to other rotational speeds. The unbalance between the mechanical and the electrical torque in each electrical machine determines rotational speed deviations.

All of the eight machines are asynchronous but, as it is stated above, units 1 and 8 are equipped with a full converter. As the VSPs converter dynamics are extremely fast compared with other components they are not included in the model. Therefore the power consumed by VSPs is directly the power reference resulting from the controller action.

FSPs are outfitted with a power electronic equipment that make possible fast start ups.

\subsection{Hydropower plant model}

\subsubsection{Conduits}

Hydropower plant hydraulic circuit is similar than pump station plant one. Upper reservoir and turbines are connected through a long penstock, divided in a manifold in four short pipes close to the Pelton turbines. All the pipes are supposed to joint in the same point in the manifold. Penstock and pipes are modelled by means of a lumped parameters approach has been used [12] while the dynamic response of open channel between turbines and lower reservoir has been neglected.

\subsubsection{Hydraulic and electric machines}

The modelled hydropower plant is equipped with four identical Pelton units, which has been individually included. PTs are modelled considering the relation between the flow, head, and nozzle opening [28]. The assumed generated torque corresponds to ideal conditions in Pelton turbines, where the absolute fluid speed is twice the runner peripheral speed for rated conditions [29]. Because the hydroelectric power plant electromagnetic transients are supposed to be very fast in comparison with the rest of the model components, they have been neglected.

\subsection{VSWTs model}

The VSWT model is composed by the aeromechanical model, the rotor mechanical model and the control schemes for a wind turbinegenerator system [30]. These 3 components are shown in Fig. 3. The IEC 61400-27-1 [31] model has not been used due to the aims of this paper (frequency regulation analysis).

\subsubsection{Wind power model}

The wind power model represents the mechanical power extracted from the wind. It is a non-linear function of pitch angle, rotor speed and wind speed [32].

The relationship between the effective mechanical power extracted from the wind and the available wind power passing through a turbine rotor plane and can be expressed by the power coefficient $C_{p}$ of the turbine [33]. The power coefficient values of the turbine are fitted with a fourth order polynomial given in [34].

\subsubsection{Blade pitch angle control}

Pitch angle control allows the control of the wind input torque, in order to enable a smooth power production and to reduce the mechanical loads. Blade pitch angle control is usually composed of two PI controllers, one of them associated with rotor speed and the other with generator power [32]. These synergistic actions have been widely used in the literature, even by manufacturers, to model pitch control, [35].

\subsubsection{Mechanical model of rotor}

The wind turbine rotor is the only mechanical element of the wind turbine components to be considered for dynamic modelling due to its influence on power fluctuations. Variations in rotor speed are caused by 


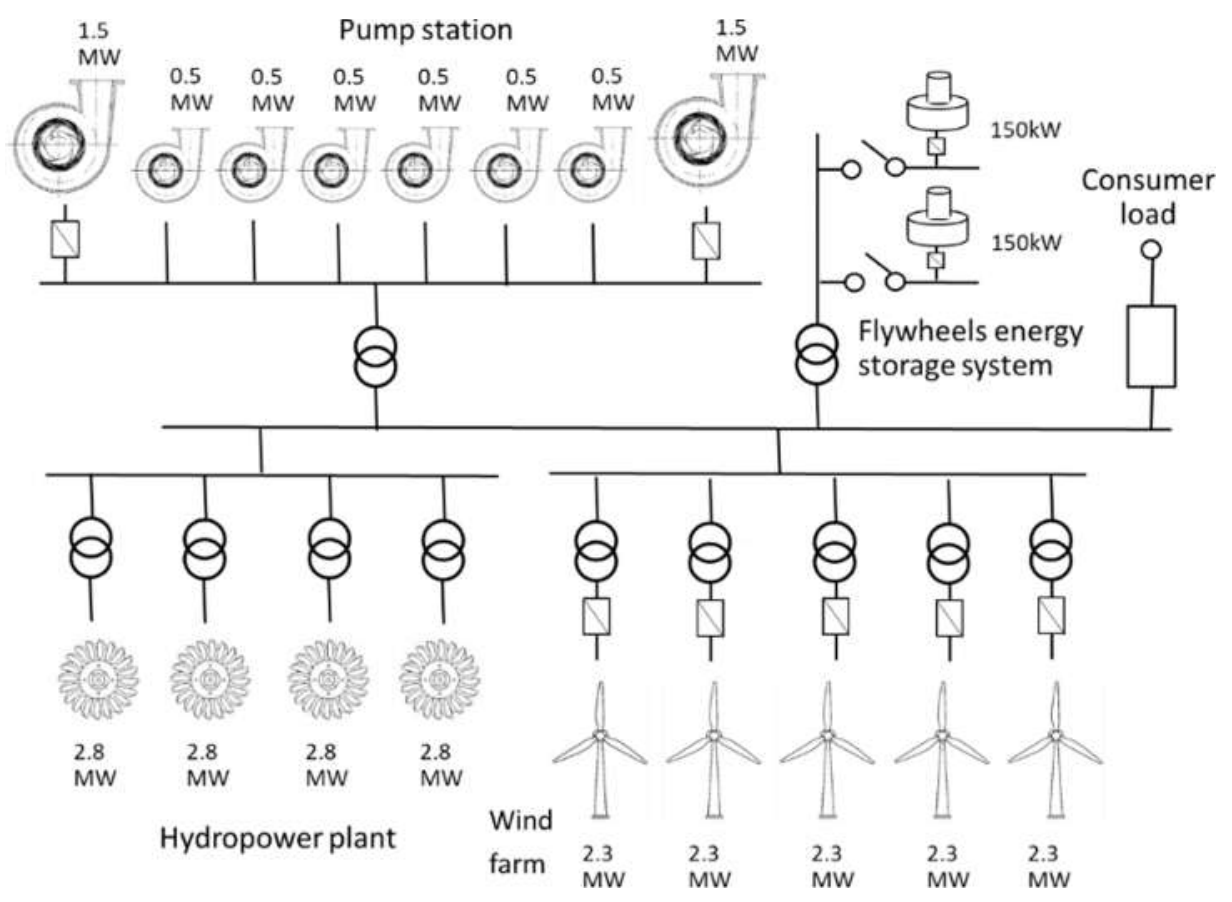

Fig. 2. El Hierro power system, simplified one-line diagram.

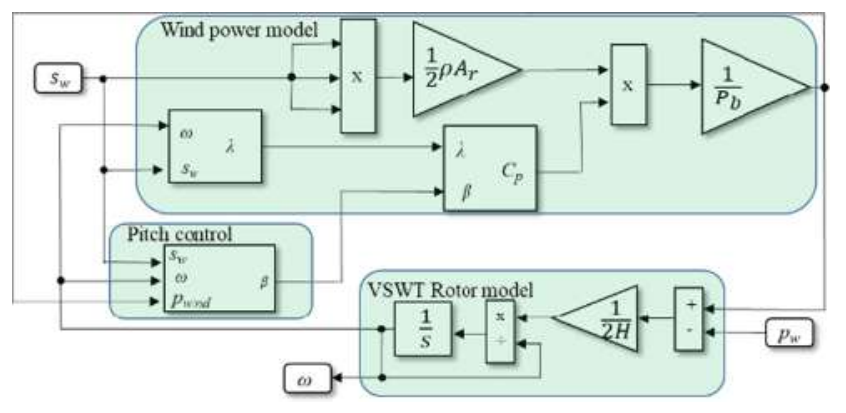

Fig. 3. Block diagram of VSWT model. the imbalance between the torque provided by the wind turbine and the torque demanded by the power converter (Fig. 3). A simple one-mass model [34] has been used due to some manufacturers recommend its use in cases where the power converter decouples the generator from the grid.

\subsection{FESS}

A flywheel model has been also developed to be included together with the rest of the system in the electric grid analysis, in order to evaluate the dynamic performance of the fast energy storage response and the power and energy availability. This model has been previously

\section{Control scheme A}

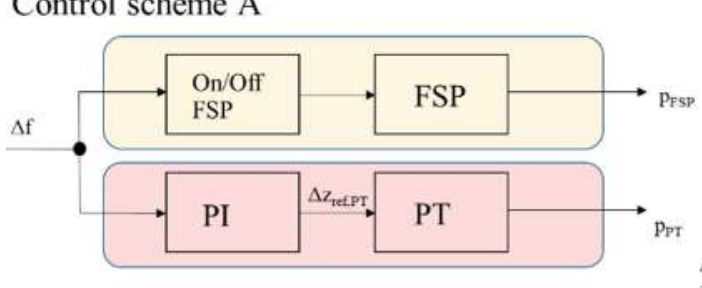

\section{Control scheme C}

Control scheme B
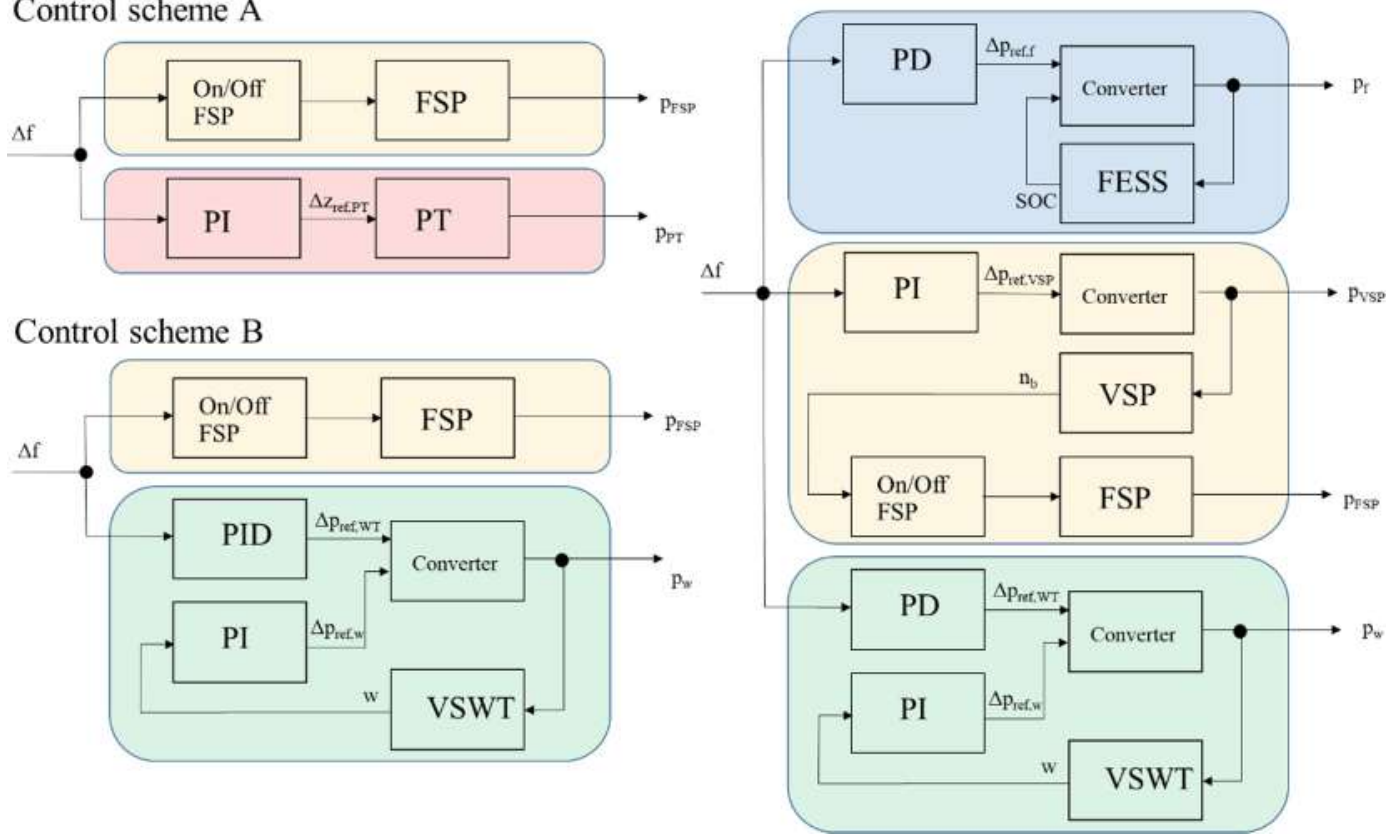

Fig. 4. Frequency controllers schemes. 
used in [8].

The flywheel model receives as input the initial State Of Charge (SOC) and the instantaneous power required, given by the control system, and provides instantaneously the power able to be supplied to the grid and the SOC or level of energy remaining.

The system is programmed to behave as a variable power system while the amount of stored energy allows to supply power to the grid. That means that, in the case of the flywheel modeled in the paper, the FESS is able to provide maximum power $(150 \mathrm{~kW}$ or $300 \mathrm{~kW})$ at full charge condition, being reduced mostly linearly until $1 / 2$ of the maximum power when the FESS is at $50 \%$ of SOC. A certain delay is also included and represents the time response of the power electronics and the control platform. Finally, the efficiency of the flywheel is included as a constant value but it could be substituted by an efficiency map if a particular technology is introduced in the model.

\section{Frequency controllers description}

Three different frequency control schemes A, B and C (Fig. 4) are introduced in the dynamic model described in the previous section. Scheme A corresponds with hydraulic short circuit operation mode. Frequency deviations are controlled only by Pelton turbines by means of an isochronous PI governor. If Pelton control action is not enough to maintain frequency into a fixed threshold, FSPs will be started up or disconnected. In Control scheme B frequency regulation is developed by VSWTs through an isochronous PID governor and PTs are only connected as synchronous condensers. FSPs are included in the same way as scheme A. The third control scheme includes a hybrid frequency regulation provided by the pump station, the VSWTs and a feasible FESS. In this case the isochronous governor PI which eliminates steady frequency deviations modifies power consumed by VSPs and VSWTs are controlled by a PD governor.

The four PTs are supposed to be operating as synchronous condensers mitigating the lack of inertia in the system in all the control schemes. In scheme A, PTs which are not supplying power operate as synchronous condensers too. Obviously, diesel units may be always disconnected, decreasing generation costs and greenhouse gas emissions.

\subsection{PT controller}

The hydroelectric plant governor has been modelled according to [25]. The main function of this governor is to control the unit speed by computing the frequency error signal, modifying the turbine nozzles.

A conventional proportional-integral (PI) controller processes the frequency deviation signal: $\Delta \mathrm{f}$. The correction action, $\Delta \mathrm{z}_{\mathrm{ref}, \mathrm{PT}}$, is translated into turbine nozzles movements, thus regulating the water flow through the penstock. The changes in the turbine nozzles due to the controller action are simulated by means of a first order transfer function $\left(\mathrm{T}_{\mathrm{s}}=0.5 \mathrm{~s}\right)$. The turbine nozzles position limits and their rates of change have been considered in the model by using a saturation element and a rate limiter respectively [28].

\subsection{VSWT controllers}

The basic idea behind most inertial response studies is to add an auxiliary signal, sensitive to frequency, to the reference power set point in VSWTs converter, momentarily increasing wind turbine output power. Practically, a $5-10 \%$ active power can be rapidly injected through inertial control under the constraint of minimal rotor speed [36]. In this paper, both inertial (derivative component of the control) and proportional control loops are proposed, allowing the release of the stored fraction of kinetic energy in rotational masses to provide earlier frequency support. This PD controller corresponds with control scheme
C. In control scheme B an integral control loop must be added to the proportional and inertial ones in order to eliminate the steady frequency error, resulting in a PID controller. Depending on the control scheme, control loop gains must be modified. Numerical values of these controller gains are listed in Table A1 in Appendix.

Owing to the existence of the wind energy conversion system, the inertial and proportional control loops add a power signal $\Delta p_{\text {ref }, W T}$ to the power reference output, to be tracked by the converter [37].

VSWT also includes a Maximum Power Point Tracking (MPPT) control consisting on a speed mode control [38] which measure error between the rotational speed and the reference rotational speed. This error is processed by a PI controller which provide a power signal $\Delta p_{r e f, w}$ to the power reference output, to be tracked by the converter [37] together with the inertial and proportional control power signal.

\subsection{VSP and FSP controllers}

In control scheme $\mathrm{C}$, the power consumed by the pump station should be modified to contribute to frequency regulation. This contribution is carried out using a dual frequency regulation system [14], which modifies the power consumed by the VSP as well as the number of FSPs operating (see Fig. 4).

On a first stage, the VSP controller consists on a PI controller that modifies the power reference tracked by the converter from the measured frequency deviation. This PI isochronous controller ensures that permanent frequency errors should be corrected. Therefore, pump station controller must always enable as the base of the new control proposed approaches. The power converters change the electric power consumption by VSPs reducing the frequency deviation. Consequently, VSPs rotor speed and mechanical power will adapt to the new electrical power. The total VSPs regulation capacity is limited to $1.2 \mathrm{MW}$ due to the normal operation power range of each VSP (0.9-1.5 MW). These power limits are related to the minimum and maximum rotational speed ( 2775 and $2970 \mathrm{rpm}$ respectively) recommended by the manufacturer and the power converter constraints. Because of these limits, the regulation VSPs capacity is not enough to balance certain changes in power demand or in the power supplied by the wind turbines. Thus, a second level control for the FSPs is also needed.

The FSP controller modifies the number of FSPs in operation according to the VSPs rotational speed. On the one hand, if the VSPs rotational speed reach the upper limit, the FSP controller starts up one FSP. The power consumed by the FSPs is increased $500 \mathrm{~kW}$, thus reducing the VSPs consumed power and rotational speed. If the increment in power consumed by the FSPs is not enough to reduce the VSPs rotational speed within the limits (due to a heavy frequency disturbance), more FSP would be started up consecutively until the VSPs rotational speed matched the limits. On the other hand, if the VSPs rotational speed fall to the lower limit, the pump shedding scheme acts until the VSPs rotational speed was within the limits.

\subsection{FESS controller}

FESS is commanded to supply/store a change in its reference power $\Delta \mathrm{p}_{\text {ref,f }}$ which is the output of a proportional derivative (PD) control of the isolated grid frequency error $\Delta \mathrm{f}$. When this error is minor than zero the controller asks FESS to inject power and the opposite if the frequency deviation is positive. This control strategy is adopted for a FESS in an isolated power system in [39] or [40].

\section{Simulations and results}

Several simulations have been carried out in order to analyse and compare the system behaviour assuming the proposed control schemes. Nine different cases, listed in Table 2, have been presented for each 
Table 2

Simulation cases description.

\begin{tabular}{ll}
\hline Control scheme & Description \\
\hline A & Frequency regulation provided by hydropower plant \\
B & Frequency regulation provided VSWTs \\
C1 & Frequency regulation provided by pump station \\
C2 & Frequency regulation provided by pump station and VSWTs \\
C3 & Frequency regulation provided by pump station and VSWTs (MPPT controller re-tuned) \\
C4 & Frequency regulation provided by pump station and FESS at a rated power of $150 \mathrm{~kW}$ \\
C5 & Frequency regulation provided by pump station and FESS at a rated power of $300 \mathrm{~kW}$ \\
C6 & Frequency regulation provided by VSWTs (MPPT controller re-tuned) and FESS at a rated power of $150 \mathrm{~kW}$ \\
C7 & Frequency regulation provided by VSWTs (MPPT controller re-tuned) and FESS at a rated power of $300 \mathrm{~kW}$ \\
\hline
\end{tabular}

Table 3

Average results using 100 synthetic signals of wind speed.

\begin{tabular}{|c|c|c|c|c|c|c|c|c|c|c|}
\hline \multirow[t]{2}{*}{ Scheme } & \multicolumn{3}{|l|}{ System } & \multicolumn{2}{|l|}{ FSP } & \multirow{2}{*}{$\begin{array}{l}\text { VSWT } \\
\omega_{\min } \text { (p.u.) }\end{array}$} & \multicolumn{4}{|l|}{ FESS } \\
\hline & $\operatorname{MFD}\left(\times 10^{-3} \mathrm{~Hz}\right)$ & $f_{\max } \mathrm{Hz}$ & $f_{\min } \mathrm{Hz}$ & On & Off & & cicles/h & $S O C_{\min }$ (p.u.) & $S O C_{\max }$ (p.u.) & Total pumped volume $\left(\mathrm{m}^{3}\right)$ \\
\hline A & 41.359 & 50.255 & 49.779 & 0 & 0 & 1.188 & - & - & - & 1917.38 \\
\hline B & 8.391 & 50.032 & 49.940 & 0 & 0 & 1.182 & - & & - & 2206.59 \\
\hline $\mathrm{C} 1$ & 14.151 & 50.145 & 49.838 & 0.32 & 0.26 & 1.188 & - & - & - & 2219.05 \\
\hline $\mathrm{C} 2$ & 8.807 & 50.063 & 49.938 & 0.34 & 0.25 & 1.187 & - & - & - & 2218.81 \\
\hline C3 & 3.128 & 50.016 & 49.966 & 0.10 & 0 & 1.185 & - & - & - & 2218.23 \\
\hline $\mathrm{C} 4$ & 13.519 & 50.066 & 49.908 & 0.23 & 0.13 & 1.188 & 0.064 & 0.374 & 0.565 & 2218.77 \\
\hline C5 & 13.479 & 50.049 & 49.936 & 0.22 & 0.12 & 1.188 & 0.040 & 0.397 & 0.539 & 2218.78 \\
\hline C6 & 3.457 & 50.016 & 49.969 & 0.10 & 0 & 1.186 & 0.008 & 0.410 & 0.500 & 2218.73 \\
\hline C7 & 3.928 & 50.018 & 49.971 & 0.10 & 0 & 1.186 & 0.007 & 0.415 & 0.500 & 2218.87 \\
\hline
\end{tabular}

Table 4

Maximum/minimum results using 100 synthetic signals of wind speed.

\begin{tabular}{|c|c|c|c|c|c|c|c|c|c|c|}
\hline \multirow[t]{2}{*}{ Scheme } & \multicolumn{3}{|l|}{ System } & \multicolumn{2}{|l|}{ FSP } & \multirow{2}{*}{$\frac{\text { VSWT }}{\omega_{\min } \text { (p.u.) }}$} & \multicolumn{4}{|l|}{ FESS } \\
\hline & $\operatorname{MFD}\left(\times 10^{-3} \mathrm{~Hz}\right)$ & $f_{\max }(\mathrm{Hz})$ & $f_{\min } \mathrm{Hz}$ & On & Off & & cicles/h & $S O C_{\min }$ (p.u.) & $S O C_{\max }$ (p.u.) & Total pumped volume $\left(\mathrm{m}^{3}\right)$ \\
\hline A & $52.92 / 33.20$ & $50.46 / 50.15$ & $49.90 / 49.51$ & $0 / 0$ & $0 / 0$ & $1.195 / 1.176$ & - & - & - & $2067.86 / 1791.80$ \\
\hline B & $23.91 / 5.39$ & $50.06 / 50.02$ & $50.00 / 49.52$ & $0 / 0$ & $0 / 0$ & $1.199 / 1.050$ & - & - & - & $2233.36 / 2057.61$ \\
\hline $\mathrm{C} 1$ & $20.95 / 11.15$ & $50.47 / 50.04$ & $49.96 / 49.56$ & $3 / 0$ & $3 / 0$ & $1.195 / 1.176$ & - & - & - & $2229.04 / 2184.13$ \\
\hline $\mathrm{C} 2$ & $13.96 / 6.37$ & $50.30 / 50.02$ & $49.98 / 49.84$ & $3 / 0$ & $3 / 0$ & $1.194 / 1.170$ & - & - & - & $2229.17 / 2183.62$ \\
\hline C3 & $5.11 / 2.45$ & $50.03 / 50.01$ & $49.99 / 49.85$ & $1 / 0$ & $0 / 0$ & $1.194 / 1.152$ & - & - & - & $2229.31 / 2166.93$ \\
\hline C4 & $18.27 / 10.96$ & $50.32 / 50.03$ & $49.97 / 49.68$ & $2 / 0$ & $1 / 0$ & $1.195 / 1.176$ & $0.262 / 0.004$ & $0.497 / 0.149$ & $1.000 / 0.500$ & $2229.03 / 2184.15$ \\
\hline C5 & $18.14 / 10.96$ & $50.18 / 50.03$ & $49.97 / 49.78$ & $2 / 0$ & $1 / 0$ & $1.195 / 1.176$ & $0.196 / 0.002$ & $0.497 / 0.107$ & $0.912 / 0.500$ & $2229.03 / 2185.08$ \\
\hline C6 & $5.83 / 2.66$ & $50.03 / 50.01$ & $49.99 / 49.89$ & $1 / 0$ & $0 / 0$ & $1.194 / 1.163$ & $0.081 / 0.000$ & $0.439 / 0.143$ & $0.500 / 0.500$ & $2229.53 / 2174.39$ \\
\hline C7 & $6.79 / 2.99$ & $50.03 / 50.01$ & $49.99 / 49.93$ & $1 / 0$ & $0 / 0$ & $1.194 / 1.168$ & $0.066 / 0.000$ & $0.439 / 0.197$ & $0.500 / 0.500$ & $2229.60 / 2176.34$ \\
\hline
\end{tabular}

Table 5

Analysis of FSP start-up/shedding in the 100 synthetic scenarios.

\begin{tabular}{llllllllllll}
\hline \multicolumn{1}{c}{ Control Scheme } \\
\cline { 2 - 9 } & A & B & C1 & C2 & C3 & C4 & C5 & C6 & C7 \\
\hline $\begin{array}{c}\text { Total synthetic scenarios with no } \\
\quad \text { FSP actions }\end{array}$ & 100 & 100 & 72 & 77 & 90 & 80 & 81 & 90 & 90 \\
$\begin{array}{c}\text { Total sum FSP start-up in the 100 } \\
\text { synthetic scenarios }\end{array}$ & 0 & 0 & 32 & 34 & 10 & 23 & 22 & 10 & 10 \\
$\begin{array}{c}\text { Total sum FSP shedding in the 100 } \\
\text { synthetic scenarios }\end{array}$ & 0 & 0 & 26 & 25 & 0 & 13 & 12 & 0 & 0 \\
\hline
\end{tabular}

simulation. As it is stated above basically there are three different control schemes. In scheme A, frequency deviations are corrected by PTs while in scheme B frequency regulation is carried out by VSWTs by means of a PID governor. In both cases FSPs manoeuvres will be needed if frequency error exceeds a fixed threshold $(52-49.5 \mathrm{~Hz})$. Nevertheless control scheme C presents different cases, C1-C7. Case C1, corresponds with the frequency control delivered only by the pump station. Cases C2 and C3, consists on pump station and VSWTs providing regulation together. In both, VSWTs are controlled by a proportional and inertial (PD) governor. Case C3 introduces a new MPPT controller adjustment

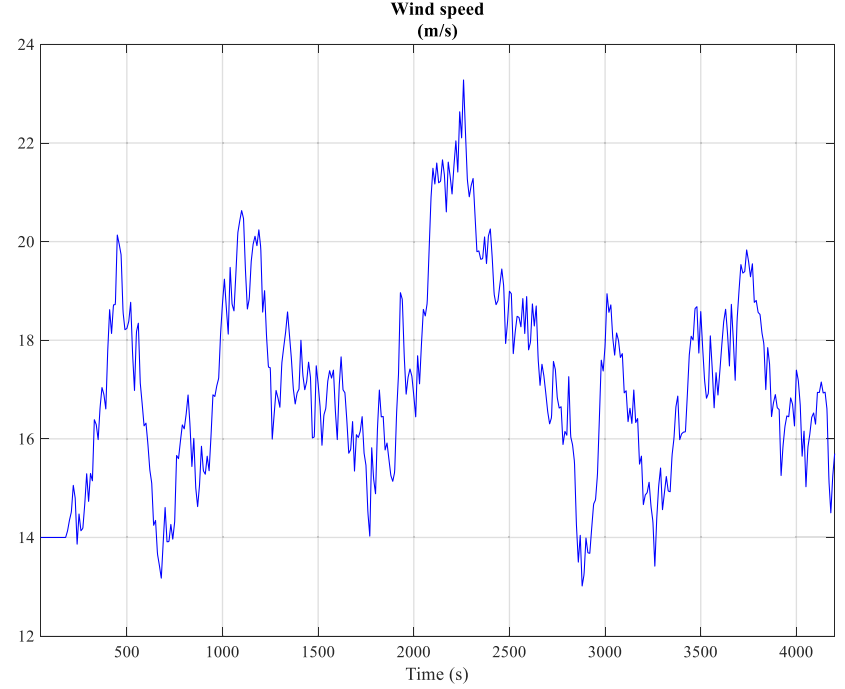

Fig. 5. Wind speed fluctuation. 

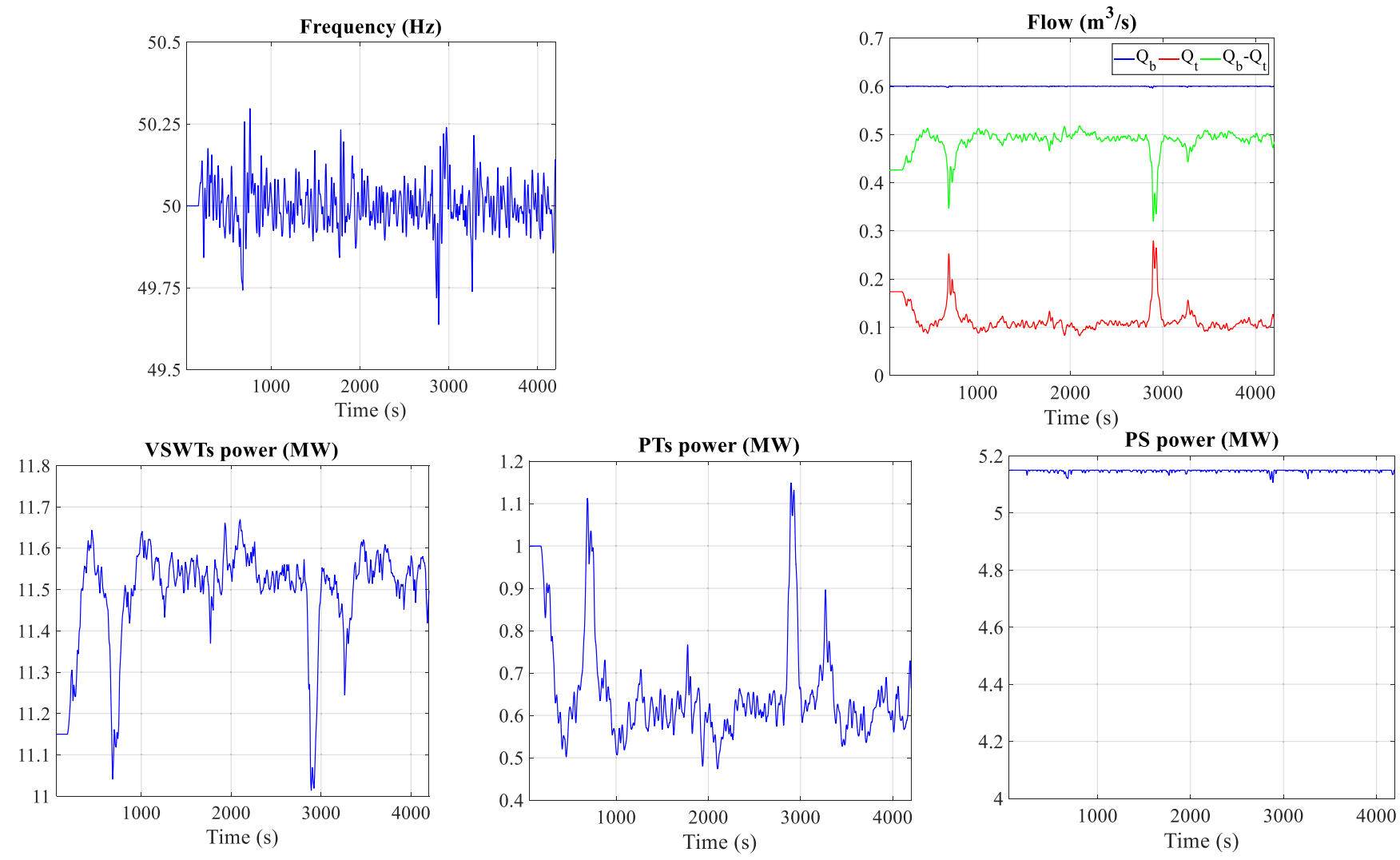

Fig. 6. Simulation results when frequency regulation is provided by PTs, operating in hydraulic short circuit mode (case A).

different than the previously proposed. In cases C4 and C5 the FESS, at a rated power of $150 \mathrm{~kW}$ (case C4) and $300 \mathrm{~kW}$ (case C5), acts along with pump station. Finally, Cases C6 and C7 involve the pump station, VSWTs and FESS at a rated power of $150 \mathrm{~kW}$ (case C6) and $300 \mathrm{~kW}$ (case C7).

Two different types of simulations have been carried out in order to analyse system response during realistic events that may occur frequently (normal operating conditions) or unlikely (abnormal operating conditions). In both cases frequency should be maintained within the limits imposed by regulation authorities for non-interconnected supply systems $(50 \mathrm{~Hz} \pm 2 \%$ for $95 \%$ of a week and $50 \mathrm{~Hz} \pm 15 \%$ for $100 \%$ of a week [41]).

\subsection{Normal operating conditions}

Wind fluctuations is one of the most common and harmful events registered in isolated systems with high wind penetration. One hundred synthetic wind speed signals have been introduced in the dynamic model as the input [16] with a duration of $4200 \mathrm{~s}$. Power demand is kept constant and equal to $7.0 \mathrm{MW}$ during all stimulations. The five VSWTs are connected to the grid; the initial power consumed by the VSPs and the number of FSPs switched on depends on the initial power injected by VSWTs according to wind speed at the beginning of each simulation. In control scheme A simulations, one Pelton turbine is connected supplying 1.0 MW so the number of FSPs switched at the start of the corresponding simulations obviously is higher than the other ones. The other three Pelton turbines are connected as synchronous condensers.

Average and maximum and minimum values of the main variables obtained from simulations are shown in Table 3 and Table 4 respectively. Table 5 contains information about start up and switch off FSPs manoeuvres registered along simulations.

In order to complete the numerical results and make easier the analysis and comparison of each control strategy some figures have been plotted coming from one of the 100 synthetic scenarios. Wind speed signal of the wind selected scenario is shown in Fig. 5.

Fig. 6 show the dynamic response of the main model variables when control scheme A is adopted. Power injected by VSWTs and power consumed by the pump station are not related with frequency variations, which are compensated only by the PT action. Frequency requirements are satisfied and FSPs shedding or start up are not needed in all scenarios, Table 5; however the total pumped flow is reduced because part of the water volume elevated by the pumps is turbined, so that the global efficiency drops.

Fig. 7 contains simulation graphical results corresponding with control scheme B. The frequency control is assumed only by the VSWTs. In this case frequency deviations are within TSO requirements and pumps maneuverers are not necessary in all the scenarios. As a counterpart, the amount of energy supplied by VSWTs is lower compared with the schemes $\mathrm{C}$ because VSWTs are aimed to control frequency alone, instead of maximizing the total energy from the wind.

Scheme C1 corresponds to the control strategy defined in [14] but in 

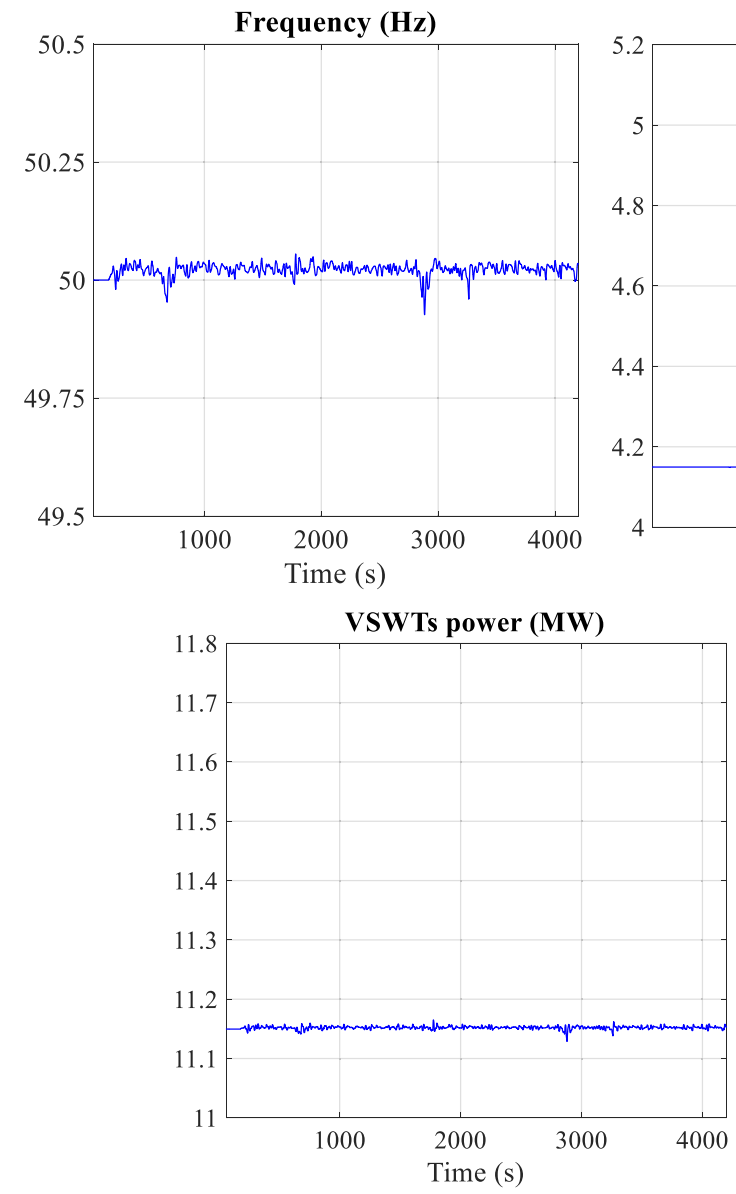
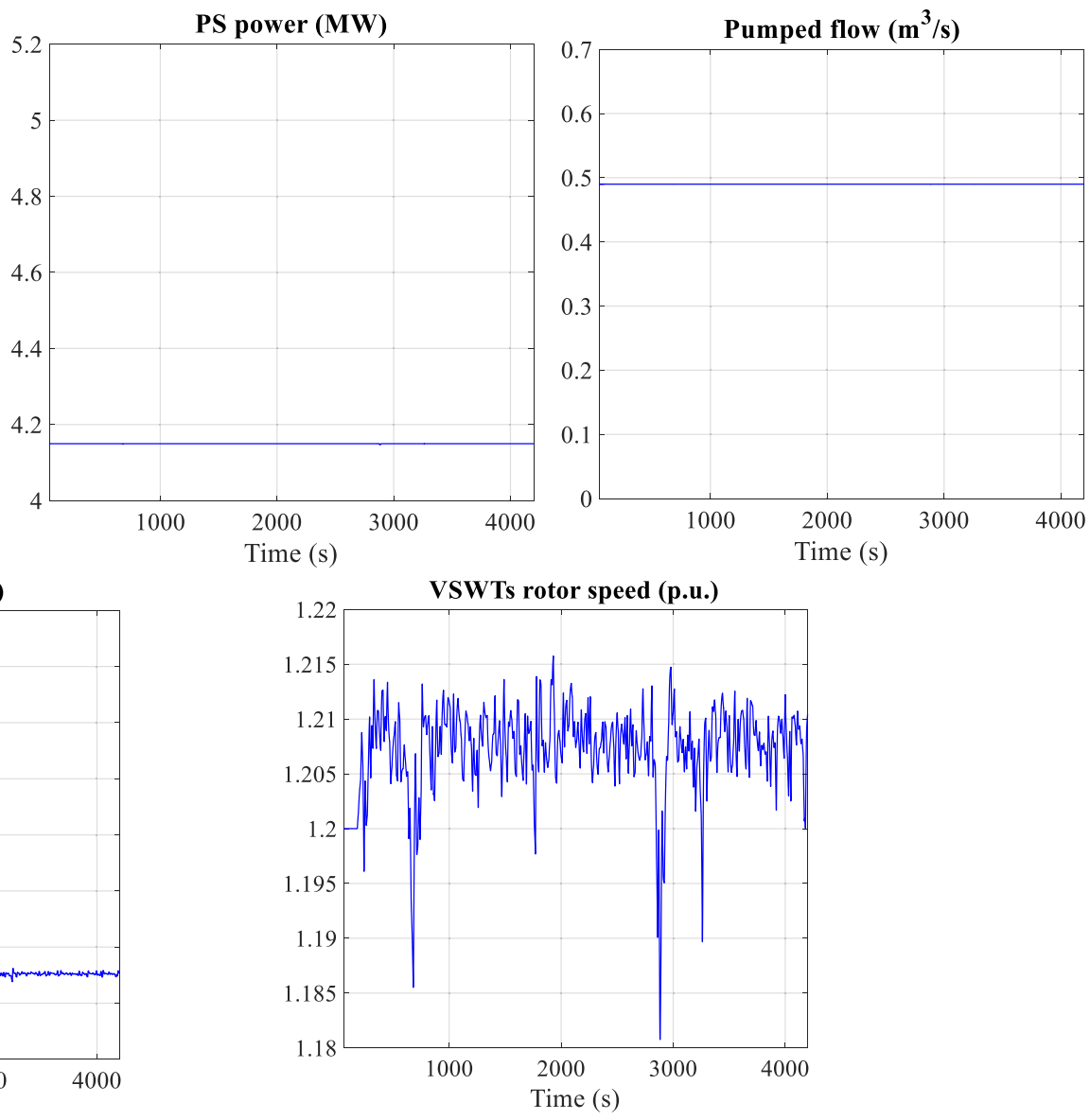

Fig. 7. Simulation results when frequency regulation is provided by VSWTs, (case B).

the present paper the number of simulations is higher. Simulations results show that this control strategy fulfils regulation requirements in all the scenarios. However the number of scenarios where it is necessary to start up or switch off FSPs is important. As it is stated in [19] load shedding is needed to be avoided, specifically in the case of pumps.

Fig. 8 shows how wind speed variations produce changes in power injected by VSWTs and consequently frequency deviations. Therefore VSPs modifies the power consumed but when their rotational speed exceed upper o lower limits it is needed to start up or switch off a FSP. When these manoeuvres take place pressure in the manifold and flow in the penstock experiment sudden changes, Fig. 9, but this dynamic efforts do not compromise hydraulic circuit functioning.

Adding VSWTs contribution to frequency control, case 2, does not provide very much better results than case 1 . Obviously frequency values, average, minimum and maximum and the number of FSPs changes are improved but this progress does not corresponds with the amount of fast energy storage available in the VSWTs converter. This fact is due to MPPT controller which diminishes VSWTs contribution to the frequency regulation in order to restore rotational speed quickly. As is can be seen in the first row of Fig. 10, VSWTs rotational speed variations are very small so it is possible to retune MPPT controller gains (Appendix) for relaxing rotational speed control and release this energy for controlling frequency deviations, case 3. Numerical and graphical results confirm that this decision provides much better system performance, reducing frequency indicators and FSPs manoeuvres with a reasonable VSWTs rotational speed.

Another way to enhance pump station regulation similar than case 2 and 3 is to incorporate a FESS in the power system (see Fig. 11). Logically numerical results improve compared with case 1 in general but they are not as good as VSWTs ones because FESS regulation capacity is lower. In these cases, 4 and 5 , it is remarkable that doubling FESS power does not mean to reduce proportionally frequency deviations or FSPs manoeuvres. This fact may be due to the PD controller adjustment that has been kept constant in either cases, or the type of the controller. At any rate this matter is out of the scope of this research. The unique relevant advantage obtained from the $300 \mathrm{~kW}$ FESS is to reduce their wear, expressed in cycles per hour, during simulations.

The last control strategy consists of activing VSWTs frequency control and connecting FESS together with the pump station. The MPPT controller gains are re-tuned according to the new control strategy and two different FESS powers, 150 and $300 \mathrm{~kW}$ are considered, case 6 and 7 respectively. It is noticeable that adding FESS to the VSWTs 

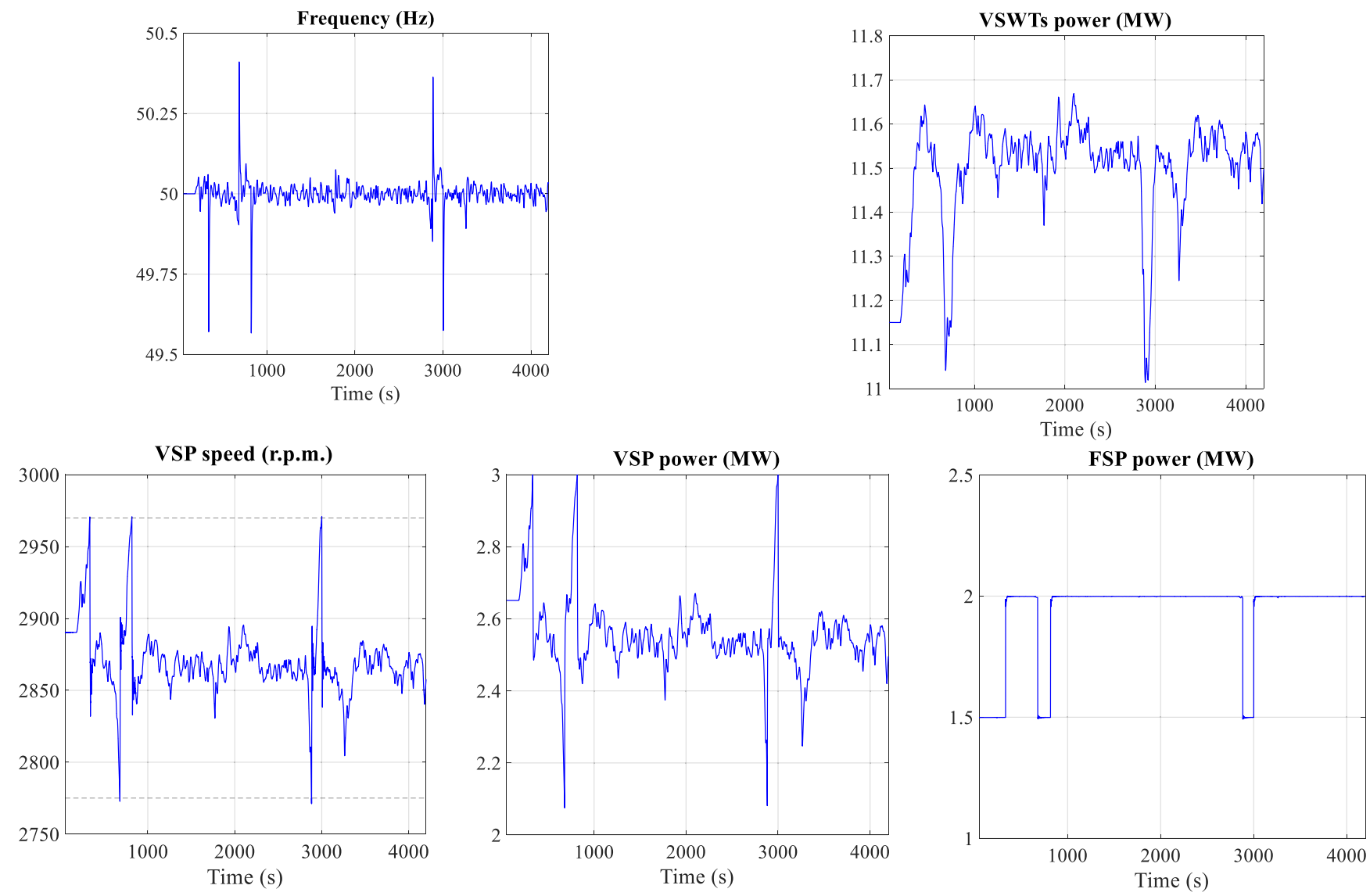

Fig. 8. Simulation results when frequency regulation is provided by pump station, case C1.
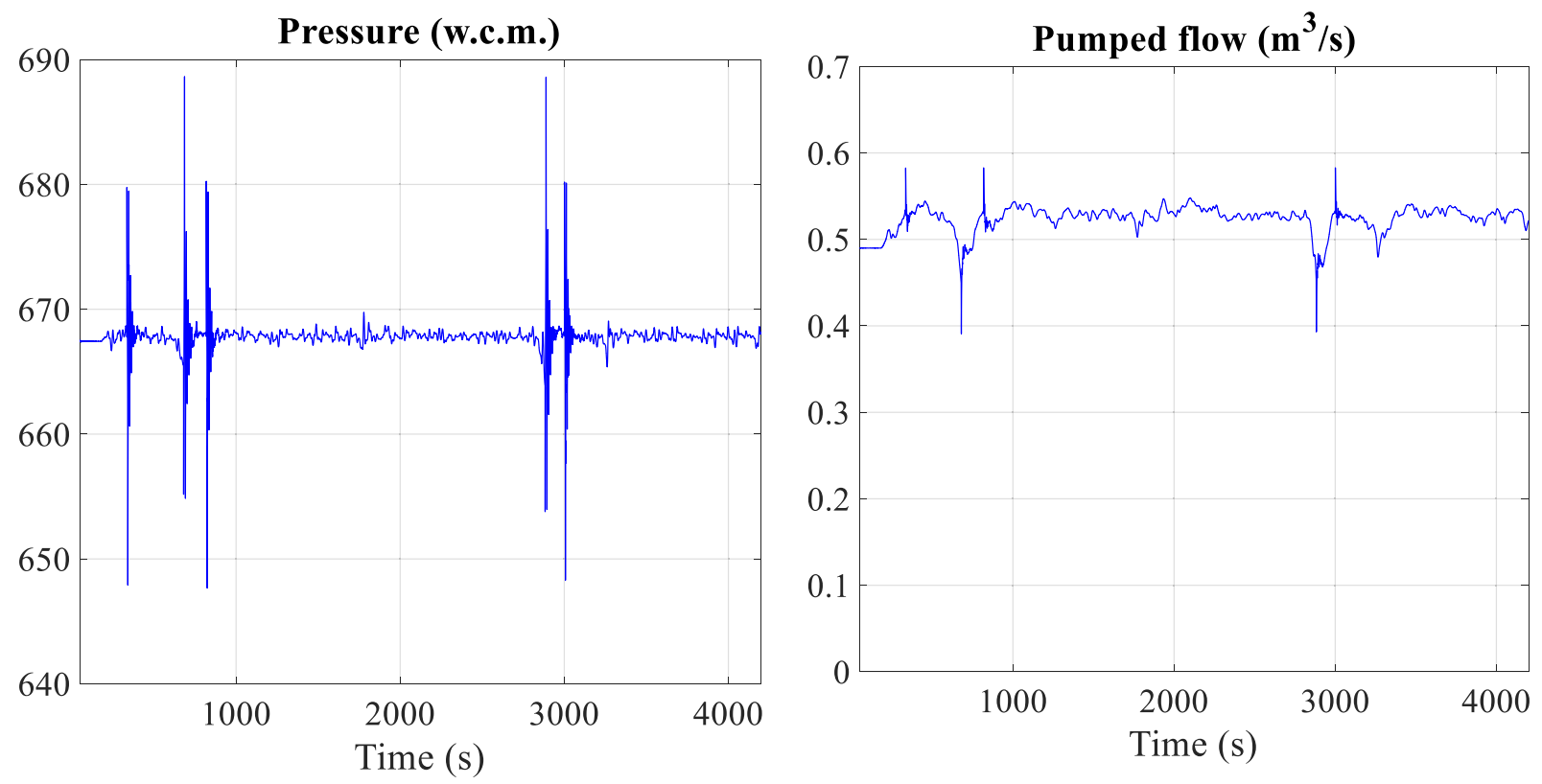

Fig. 9. Pressure and pumped flow when frequency regulation is provided by pump station, case C1. 

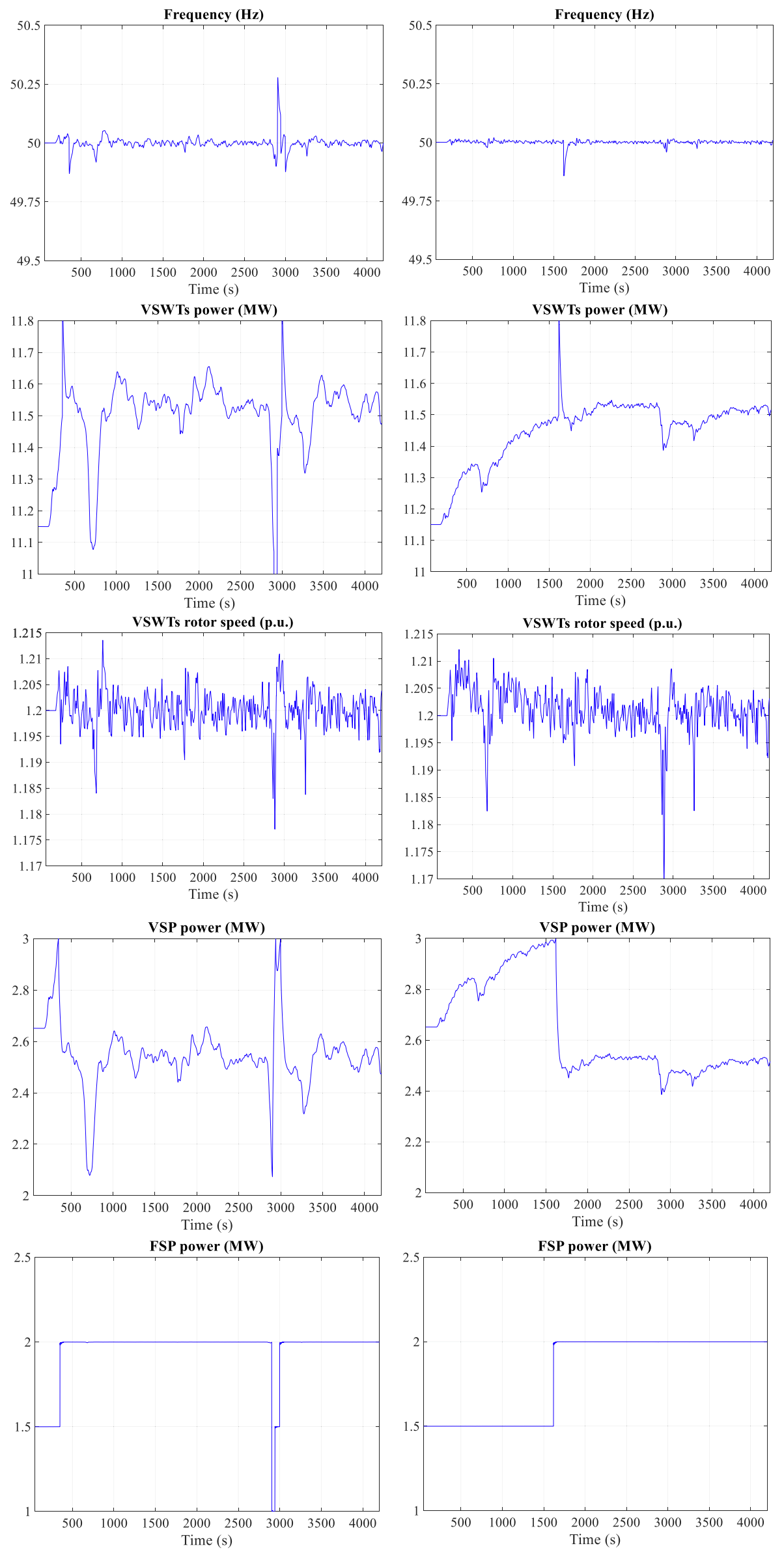


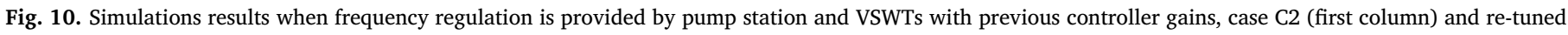
controller gains, case C3 (second column).

contribution (Case 3) does not really improve frequency results, indeed the MFD deteriorates with FESS frequency control contribution. This is because both, VSWTs and FESS, supply the same inertial control action and they negatively interfere. But it is also true that the maximum and minimum frequency values are reduced.

Another point to take into account is the SOC of flywheels during simulations. In Fig. 12 it can been checked that the flywheels almost completely discharge. Flywheels need to be continuously providing and absorbing power from the net, otherwise friction losses in their rotating mass induces their discharge in a short period of time. When the FESS are connected together with VSWTs, which are providing frequency control, their role in control is limited so it can be affirmed that this control strategy does not make sense. Probably in this case replacing flywheels by another fast storage system as batteries or supercapacitors would be a good solution. Perhaps another control strategy which may introduce different hierarchy actions for FESS and VSWTs would be an interesting proposal too. Both propositions are out of the scope of this paper but obviously they are an attractive line of future investigation.

Summarizing, from the frequency point of view, all the control schemes fulfil TSO requirements but hydraulic short circuit scheme present worse MFD, $f_{\max }$ and $f_{\min }$ values. This is due to frequency converters make the frequency regulation faster in schemes B and C. Control scheme B presents good results, only exceeded by schemes C3, C6, C7.

Analysing the global efficiency of the schemes, shown by the total volume of water elevated to the upper reservoir during the simulation, schemes C present better figures. For example, average pumped volume across the 100 scenarios for hydraulic short circuit operation mode (scheme A) is $300.8 \mathrm{~m}^{3}$ lower than average pumped volume in scheme $\mathrm{C} 3$. In the same way, average pumped volume corresponding to scheme B is $11.6 \mathrm{~m}^{3}$ lower than pumped volume in scheme C3. These water volume differences involve energy losses. Assuming the number of hours that the system has being operating in hydraulic short-circuit mode during 2018 listed in Table 1, energy losses associated to control scheme A operation would be $1344.6 \mathrm{MWh}$ and associated to control scheme B 52.0 MWh, compared with scheme C3 results.

The main drawback of control schemes $C$ is the number of FSPs manoeuvres. For example, from results listed in Table 3 and assuming 2018 data, control scheme C3 would involve 188 pump start up actions more than control schemes A and B.

\subsection{Abnormal operating conditions}

This test is carried out by means of a sudden disconnection of the generator with the highest power connected to the net, one of the five wind generators (2.3 MW). For this simulation, the five VSWTs are connected supplying their rated power, the power demand is $6.5 \mathrm{MW}$ and the power consumed by the power station is $5 \mathrm{MW}: 2 \times 1.25 \mathrm{MW}$ by VSPs and $5 \times 0.5$ MW by FSPs. Table 6 compiles the main simulation figures for all the cases described above, Fig. 13 shows main model variables temporary response in cases A and B and Fig. 14 shows the same model variables for C1, C3, C4 and C6.

In this situation, the control schemes $\mathrm{C}$ which includes the VSWTs contribution to the frequency regulation (C2, C3, C6 and C7) present a significant improvement compared with A and B. Comparing schemes
C, when the wind generator disconnects all the controllers, pump station, VSWTs and FESS, are asked to supply their whole reserve so the best NADIR and Rate of Change of Frequency (RoCof) correspond with case C7, which is the faster control strategy too. But comparing case 3 and case 7 results, the contribution of flywheels is not relevant again. As the FESS capacity is small, 150 or $300 \mathrm{~kW}$, the increment of the NADIR and decrement of RoCoF are limited. Nevertheless the NADIR and RoCoF values experience a great improvement when the VSWTs control frequency deviations.

VSWTs and FESS contribution to frequency regulation in schemes $\mathrm{C}$ acts at the initial moment after the incident but they have to recover their initial rotational speed and SOC. Therefore the loss of generation must be assumed by the pump station in all the cases; shedding of all the FSPs cannot be avoided. In case A, Pelton turbine has an important reserve $(2.8-1.0=1.8 \mathrm{MW})$ but as the RoCof is high and the nozzles movements are not so fast, NADIR exceeds the threshold $(49.5 \mathrm{~Hz})$ and pump shedding cannot be avoided. In case B, VSWTs contribution is limited by converter constraints.

\section{Conclusions}

The isolated power system of El Hierro Island consists of diesel units and a hybrid W- PSHP. In recent years renewable participation has been increased by operating PSHP in hydraulic short circuit mode. In this paper different frequency control schemes are proposed so that Pelton units contribution to the frequency control can be substituted, avoiding energy losses owing to short-circuit operation. The control schemes are developed using (i) pumping station regulation capacity, (ii) kinetic energy stored in the VSWTs rotors and (iii) a new FESS. The control scheme corresponding to hydraulic short-circuit operation mode has been also considered in order to quantify the improvements associated to the new control schemes. Nine different control cases have been presented resulting of the combination of these control schemes.

In order to analyse and compare the mentioned cases a dynamic model has been developed in Matlab Simulink. The model includes the power system, the hydropower plant, the pump station, the VSWTs and the FESS and reproduces the frequency deviation by means of an aggregate inertial model. Two types of simulations have been carried out: 100 different scenarios of fluctuations in the power supplied by wind turbines due to variations in wind speed and a sudden disconnection of one of the VSWTs.

Variable wind simulation results show that hydraulic short circuit operation presents correct responses in terms of frequency avoiding FSPs manoeuvres. However it involves important energy losses due to the reduction of the volume of water elevated to the upper reservoir. When the frequency regulation is only provided by VSWTs, control scheme B, simulation results improves case A, avoiding FSPs manoeuvres and carrying a reduced loss of energy. Regarding schemes C, the regulation provided only by the pump station fulfils frequency requirements but it implies starting up or shedding FSPs in an important number of scenarios. The combination of the pump station and the VSWTs contribution to the frequency control improves results, including the reduction of FSPs manoeuvres, but it is necessary to retune MPPT controller gains for relaxing rotational speed control and release this energy for controlling frequency deviations. The enhancement in 

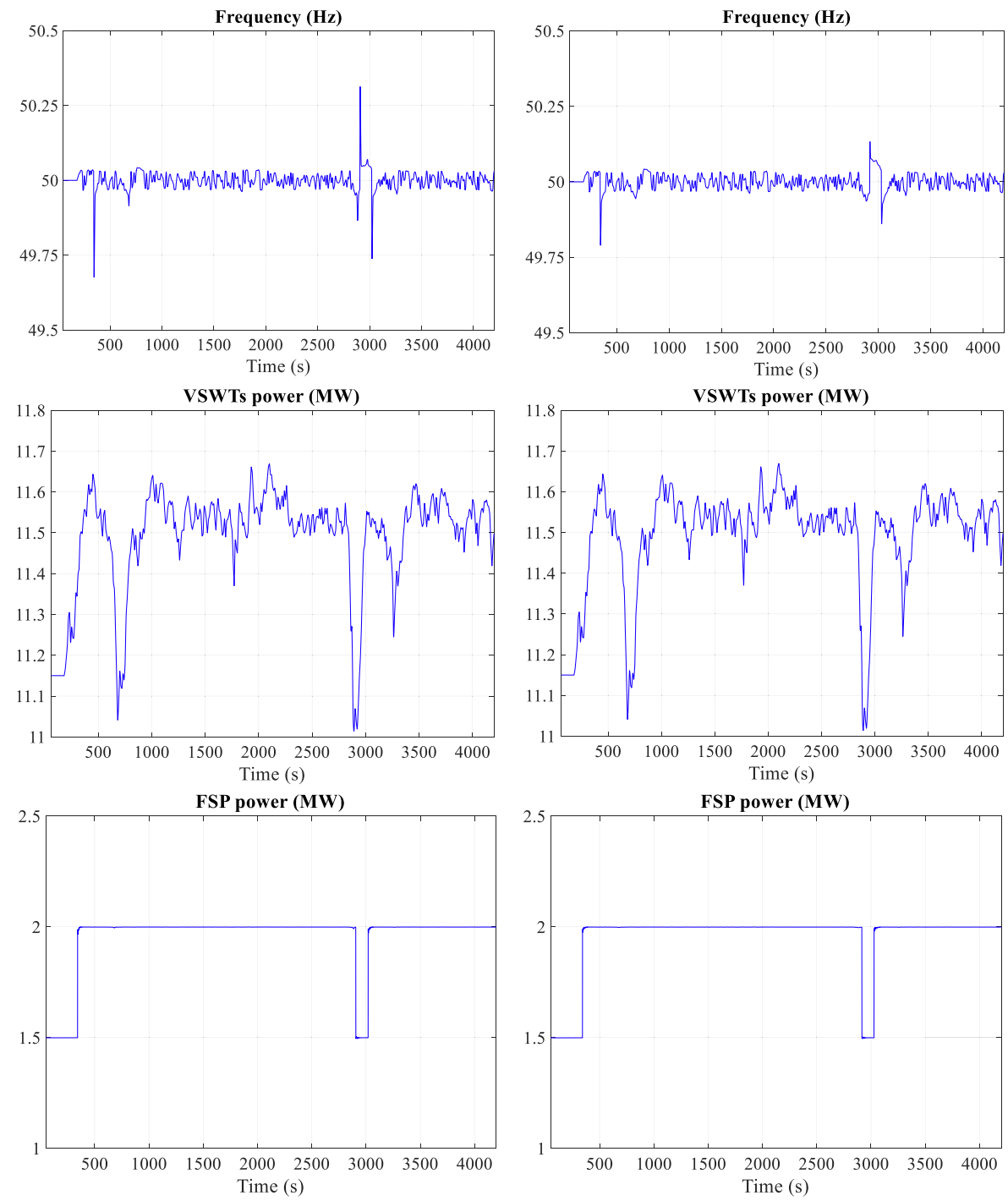

FESS power (MW)
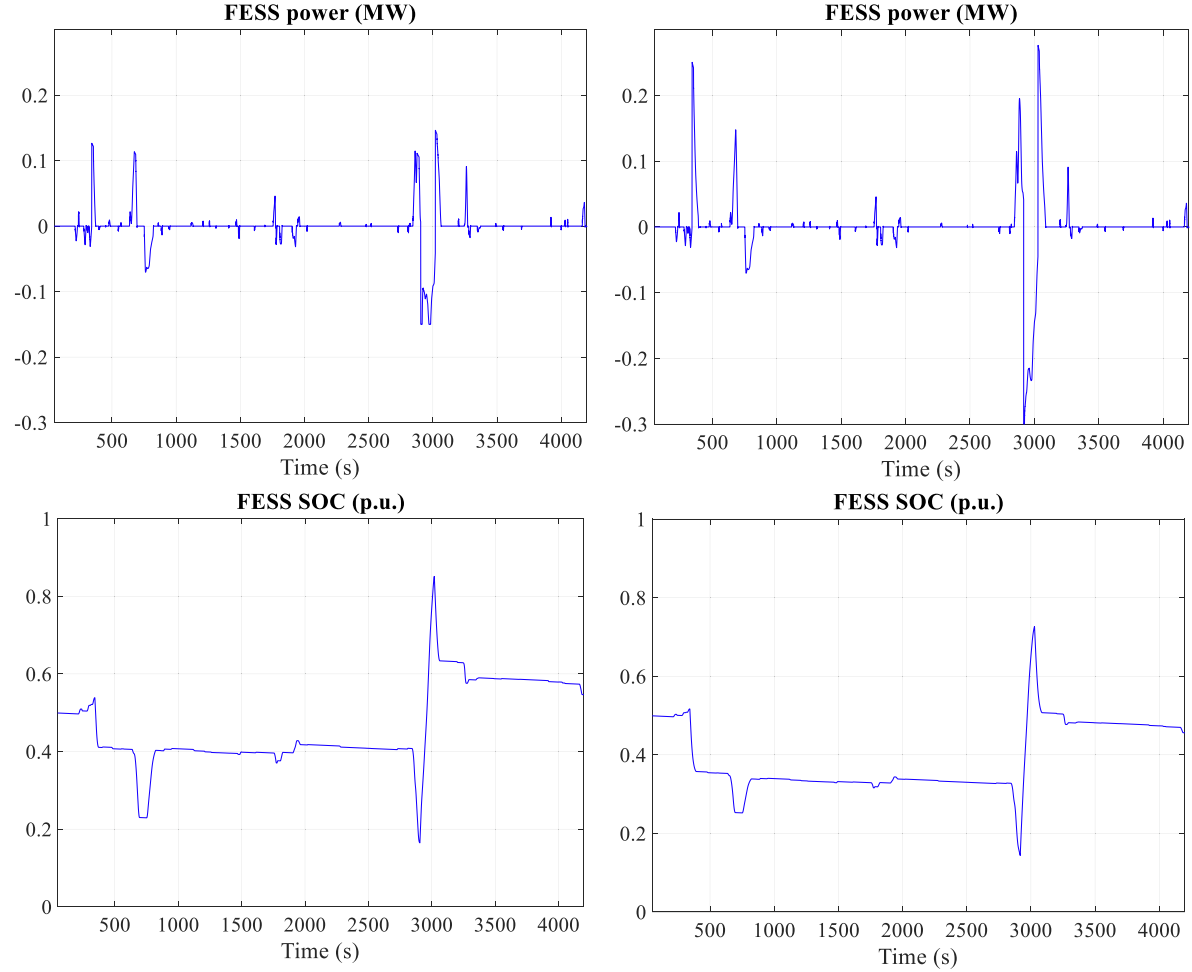


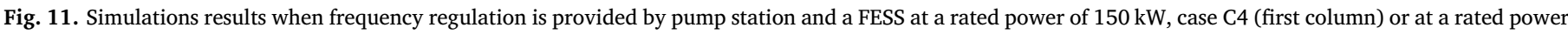
of $300 \mathrm{~kW}$, case C5 (second column).
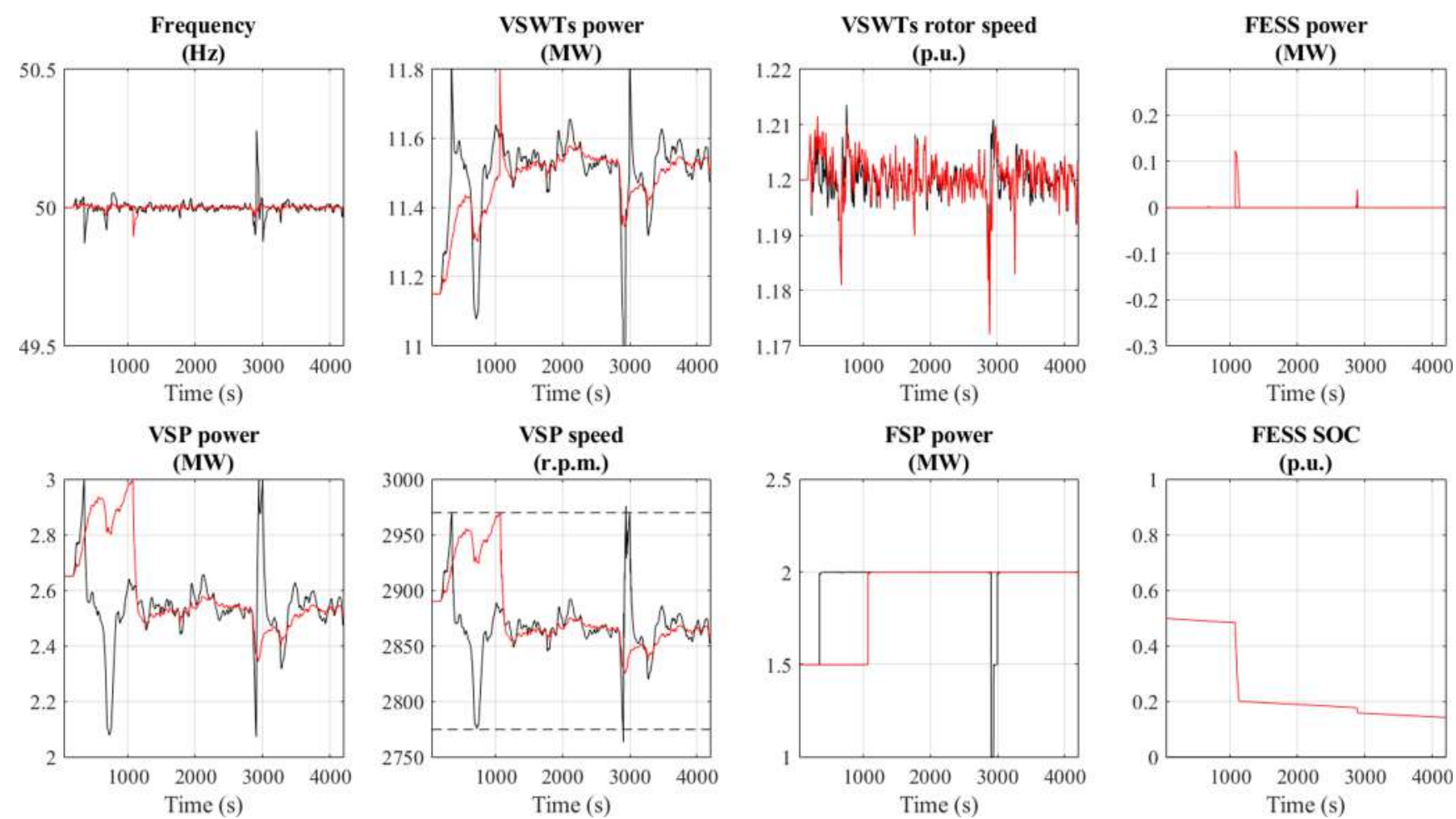

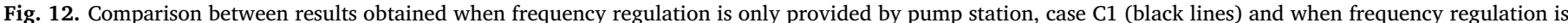

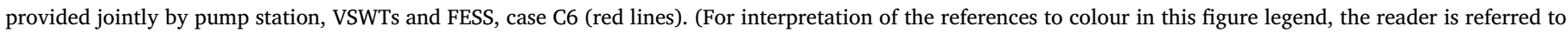
the web version of this article.)

Table 6

Nadir, RoCoF and frequency settling time when a sudden disconnection of a VSWT takes place.

\begin{tabular}{llll}
\hline Scheme & NADIR $(\mathrm{Hz})$ & $\operatorname{RoCoF}(\mathrm{Hz} / \mathrm{s})$ & $T_{ \pm 0.15 \mathrm{~Hz}}(\mathrm{~s})$ \\
\hline A & 45.953 & -1.577 & 64.92 \\
B & 47.205 & -0.966 & 37.09 \\
C1 & 46.427 & -1.427 & 24.32 \\
C2 & 49.321 & -0.633 & 15.55 \\
C3 & 49.322 & -0.633 & 12.79 \\
C4 & 46.894 & -1.343 & 21.34 \\
C5 & 47.222 & -1.259 & 18.09 \\
C6 & 49.353 & -0.594 & 11.68 \\
C7 & 49.386 & -0.554 & 11.23 \\
\hline
\end{tabular}

frequency values by adding the FESS to the pump station frequency control is positive too but not as good as the one obtained with VSWTs. This is due to the reduce FESS power capacity (150 and $300 \mathrm{~kW})$. It is remarkable that doubling the number of flywheels does not mean to reduce proportionally frequency deviations or FSPs manoeuvres. This fact may be due to the FESS PD controller adjustment has been kept constant in either cases, or the type of the controller. Finally, the benefits of adding the FESS to VSWTs are very limited. This is because both, VSWTs and FESS, supply the same inertial control action and they negatively interfere. Moreover, as the FESS contribution to the frequency regulation is very low, flywheels almost completely discharge. Hence in this case replacing flywheels by another fast storage system as batteries or supercapacitors introducing another control strategy would be a good solution for developing in a future research work.

Wind turbine disconnection simulation results are in general similar to variable wind speed ones. Pump shedding cannot be avoided in any case. In cases C, pump station frequency control fulfils TSO requirements but the addition of VSWTs or/and FESS improves the NADIR and the RoCoF.

Therefore, these alternative control schemes seem to be a good method to increase renewable energy participation in El Hierro Island, by reducing the inherent costs of hydraulic short circuit operation mode and making the best use of the existing wind resource. 


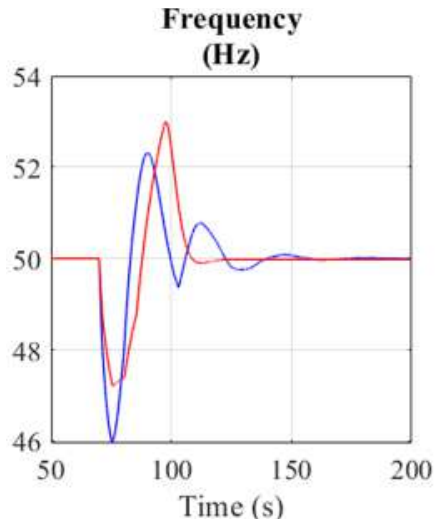

PTs power

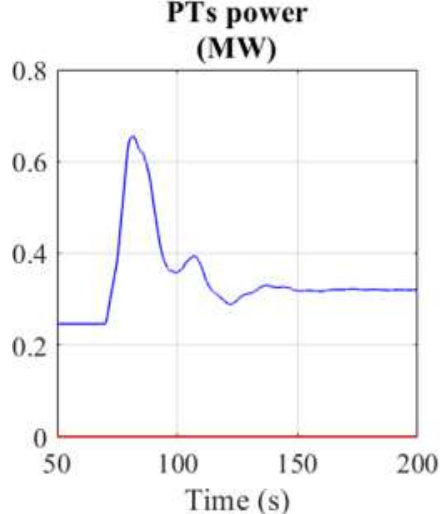

VSWT power

(MW)

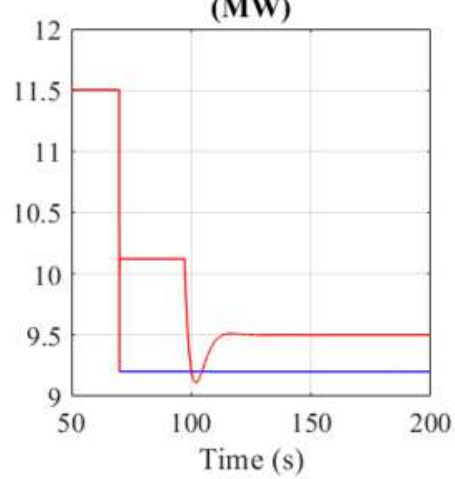

FSP power

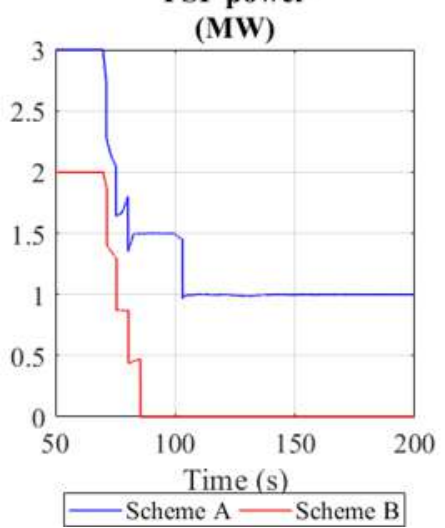

VSWT rotational speed (r.p.m.)

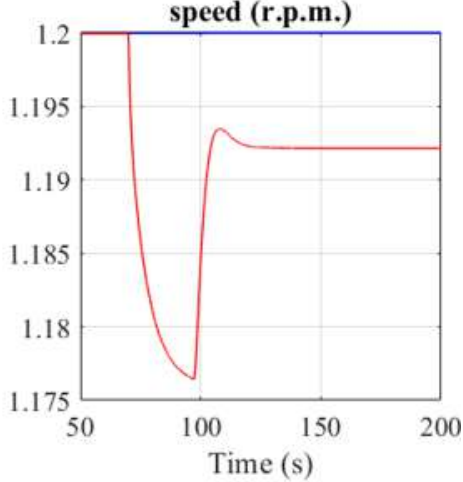

FEES power (MW)

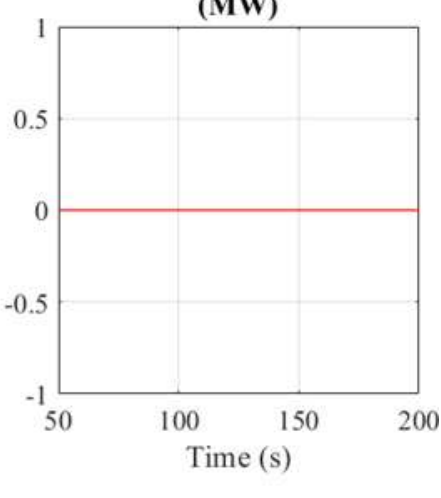

Fig. 13. Simulation results when a sudden disconnection of a VSWT (2.3 MW) takes place schemes A and B.
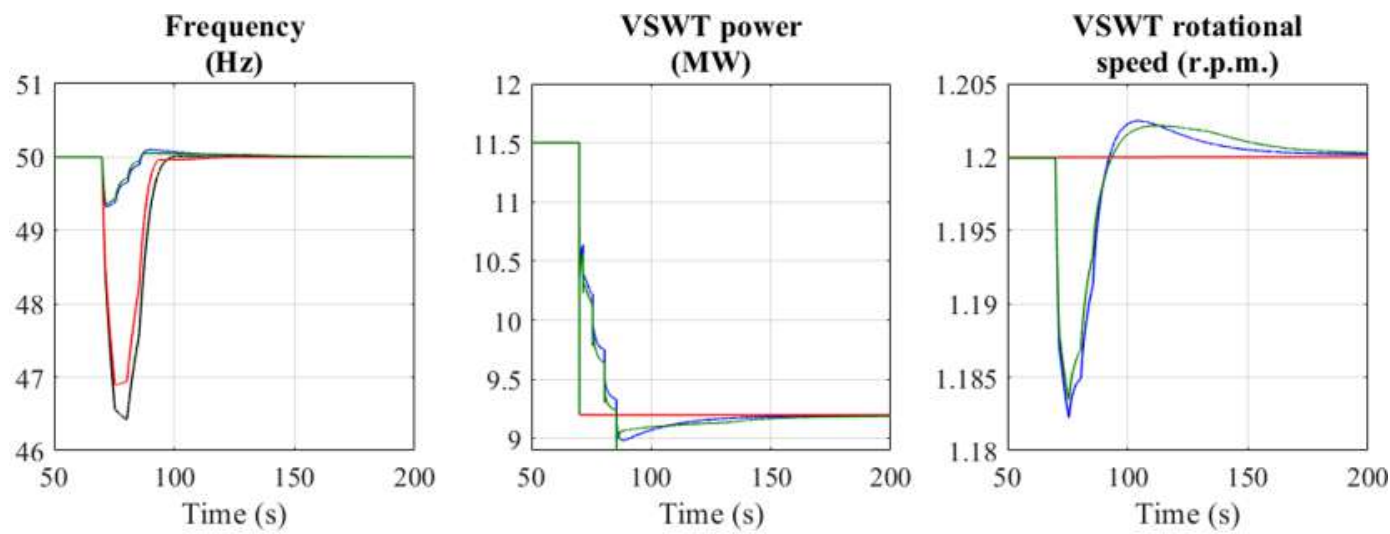

VSP power

(MW)

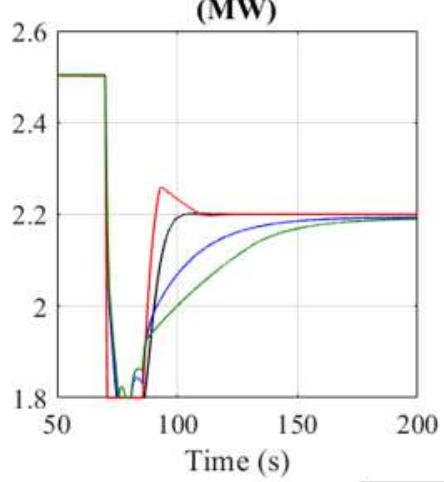

FSP power

(MW)

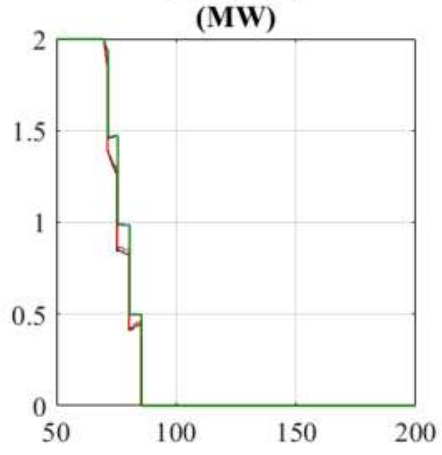

FEES power

(MW)

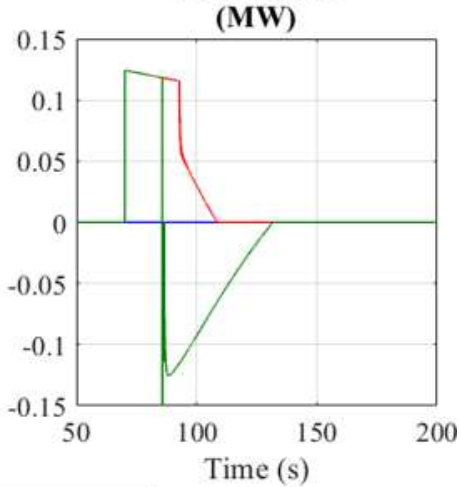

Scheme $\mathrm{Cl} \longrightarrow$ Scheme $\mathrm{C} 3 \longrightarrow$ Scheme $\mathrm{C} 4-$ Scheme $\mathrm{C} 6$

Fig. 14. Simulation results when a sudden disconnection of a VSWT (2.3 MW) takes place. 


\section{Declaration of Competing Interest}

The authors declare no conflict of interest.

\section{Acknowledgements}

The work presented in this paper has been partially funded by the

\section{Appendix A}

Spanish Ministry of Economy and Competitiveness under the project 'Value of pumped-hydro energy storage in isolated power systems with high wind power penetration' of the National Plan for Scientific and Technical Research and Innovation 2013-2016 (Ref. ENE2016-77951-

$\mathrm{R})$.

Table A1

FESS, FSP, VSWTs and PTs controller gains.

\begin{tabular}{|c|c|c|c|c|c|c|c|c|c|c|c|}
\hline \multirow[t]{3}{*}{ Scheme } & \multicolumn{11}{|l|}{ Gain } \\
\hline & \multicolumn{2}{|c|}{ FESS } & \multicolumn{2}{|l|}{ VSP } & \multicolumn{5}{|c|}{ VSWTs } & \multicolumn{2}{|l|}{ PTs } \\
\hline & $K_{f, P}$ & $K_{f, D}$ & $K_{V S P, P}$ & $K_{V S P, I}$ & $K_{w, P}$ & $K_{w, I}$ & $K_{w, D}$ & $K_{\omega, P}$ & $K_{\omega, I}$ & $\delta$ & $\mathrm{T}_{\mathrm{r}}$ \\
\hline A & - & - & - & - & - & - & - & - & - & 0,6 & 2 \\
\hline B & - & - & - & - & 1.00 & 0,25 & 0,75 & 0,10 & 0.0150 & - & - \\
\hline $\mathrm{C} 1$ & - & - & 10 & 2 & - & - & - & 0,10 & 0.0150 & - & - \\
\hline $\mathrm{C} 2$ & - & - & 10 & 2 & 2.00 & - & 1.50 & 0.10 & 0.0150 & - & - \\
\hline $\mathrm{C} 3$ & - & - & 10 & 2 & 2.00 & - & 1.50 & 0.10 & 0.0015 & - & - \\
\hline $\mathrm{C} 4$ & 25 & 5 & 10 & 2 & - & - & - & 0.10 & 0.0150 & - & - \\
\hline C5 & 25 & 5 & 10 & 2 & - & - & - & 0.10 & 0.0150 & - & - \\
\hline C6 & 25 & 5 & 10 & 2 & 2.0 & - & 1.50 & 0.10 & 0.0030 & - & - \\
\hline C7 & 25 & 5 & 10 & 2 & 2.0 & - & 1.50 & 0.10 & 0.0045 & - & - \\
\hline
\end{tabular}

\section{References}

[1] Wu T. Wind power integration and operation technique. Beijing; 2013

[2] Sigrist L, Rouco L, Echavarren FM. A review of the state of the art of UFLS schemes for isolated power systems. Electrical Power Energy Syst 2018;99:525-39.

[3] Delille G, Francois B, Malarange G. Dynamic frequency control support by energy storage to reduce the impact of wind and solar generation on isolated power system's inertia. IEEE Trans Sustainable Energy 2012;3(4):931-9.

[4] Rodrigues E, Osório G, Godina R, Bizuayehu A, Lujano-Rojas J, Catalão J. Grid code reinforcements for deeper renewable generation in insular energy systems. Renew Sustain Energy Rev 2016;53:163-77.

[5] Ye B, Zhang K, Jiang J, Miao L, Li J. Towards a 90\% renewable energy future: a case study of an island in the South China Sea. Energy Convers Manage 2017;142:24-41.

[6] Sebastián R, Peña Alzola R. Flywheel energy storage systems: review and simulation for an isolated wind power system. Renew Sustain Energy Rev 2012;16(9):6803-13.

[7] Hamsic N, Schmelter A, Mohd A, Ortjohann E, Schultze E, Tuckey A, Zimmermann J. Increasing renewable energy penetration in isolated grids using a flywheel energy storage system. Setubal, Portugal; 2007.

[8] Sarasúa José I, Torres B, Pérez-Díaz JI, Lafoz M. Control strategy and sizing of a flywheel energy storage plant for the frequency control of an isolated wind-hydro power. In: 15th wind integration workshop, Vienna; 2016.

[9] Kaldellis J, Kavadias K, Christinakis E. Evaluation of the wind - hydro energy so lution for remote islands. Energy Convers Manage 2001;42(9):1105-20.

[10] Singh R, Chelliah T, Agarwal P. Power electronics in hydro electric energy systems A review. Renew Sustain Energy Rev 2014;32:944-59.

[11] Valavi M, Nysveen A. Variable-speed operation of hydropower plants. IEEE Ind Appl Mag 2018:18-27.

[12] Nicolet C, Pannatier Y, Kawkabani B, Schwery A, Avellan F, Simond J-J. Benefits of variable speed pumped storage units in mixed islanded power network during transient operation. In: 16th annual hydro conference, Lyon, France; 2009.

[13] Suul JA, Uhlen K, Undeland T. Wind power integration in isolated grids enabled by variable speed pumped storage hydropower plant. Singapore; 2008.

[14] Sarasúa JI, Martínez-Lucas G, Platero CA, Sánchez-Fernández JÁ. Dual frequency regulation in pumping mode in a wind-hydro isolated system. Energies 2018(11):1-17.

[15] Martínez-Lucas G, Sarasúa JI, Sánchez-Fernández JÁ. Frequency regulation of hybrid wind-hydro power plant in an isolated power system. Energies 2018;11(239):1-25.

[16] Martínez-Lucas G, Sarasúa JI, Sánchez-Fernández JÁ. Eigen analysis of wind-hydro joint frequency regulation in an isolated power system. Electrical Power Energy Syst 2018;103:511-24.

[17] Red Electrica de España. El Hierro - Seguimiento de la demanda de energía eléctrica, [Online]. Available: < https://demanda.ree.es/visiona/canarias/el hierro/total $>$. [Accessed 3rd january 2019].

[18] Red Electrica de España. La isla de El Hierro cubre su demanda de electricidad con energía $100 \%$ renovable durante 18 días consecutivos; 2018. [Online].
Available: < https://www.ree.es/es/sala-de-prensa/notas-de-prensa/2018/02/laisla-de-el-hierro-cubre-su-demanda-de-electricidad-con-energia-100-por-100renovable-durante-18-dias > . [Accessed 19th december 2018].

[19] Marrero Quevedo A, Medina Domínguez EJ, de León Izquier JM, Corujo de León R Santos Arozarena P, Gil Moreno J, Castañeda Quintero A, González Hernández J. Gorona del Viento wind-hydro power plant. In: 3rd international hybrid power systems workshop, Tenerife, Spain; 2018.

[20] Martinez de Lucas G. Frequency control of hybrid wind-hydro power plants with long conduits in isolated power systems Thesis Madrid: Universidad Politécnica de Madrid; 2018.

[21] Hamdia Afgan N, de Carvalho MCR, editors. New and renewable technologies for sustainable development. New York, USA: Springer Science \& Business Media; 2002.

[22] Garcia Latorre FJ, Quintana JJ, de la Nuez I. Technical and economic evaluation of the integration of a wind-hydro system in El Hierro island. Renewable Energy 2019;134:186-93.

[23] Chazarra M, Pérez-Díaz JI, García-González J. Optimal energy and reserve scheduling of pumped-storage power plants considering hydraulic short-circuit operation. IEEE Trans Power Syst 2017;32(1):344-53.

[24] Platero C, Nicolet C, Sánchez J, Kawkabani B. Increasing wind power penetration in autonomous power systems through no-flow operation of Pelton turbines. Renewable Energy 2014:68:515-23.

[25] Mansoor S, Jones D, Bradley F, Jones G. Reproducing oscillatory behaviour of a hydroelectric power station by computer simulation. Control Eng Pract 2000;8(11):1261-72.

[26] O'Sullivan J, Rogers A, Flynn D, Smith P, Mullane A, O'Malley M. Studying the maximum instantaneous non-synchronous generation in an island system-. frequency stability challenges in Ireland. IEEE Trans Power Syst 2014;29(6):2943-51.

[27] Chaudhry MH. Governing stability of a hydroelectric power plant. Water Power 1970:131-6.

[28] IEEE Working Group. Hydraulic turbine and turbine control models for system dynamic studies. IEEE Trans Power Syst 1992;7(1):167-79.

[29] Martínez-Lucas G, Sarasúa JI, Sánchez JÁ, Wilhemi JR. Power-frequency control of hydropower plants with long penstocks in isolated systems with wind generation. Renewable Energy 2015;83:245-55.

[30] Jing X. Modeling and control of a DFIG for wind turbine-generators systems Thesis Milwakee, Wisconsin: Marquette University; 2012

[31] International Electrotechnical Commission Std. IEC 61400-27-1 Electrical simulation models - Wind turbines; 2015

[32] Honrubia-Escribano A, Gómez-Lázaro E, Fortmann J, Sørensen P, Martin-Martinez S. Generic dynamic wind turbine models for power system stability analysis: a comprehensive review. Renew Sustain Energy Rev 2018;81(2):1939-52.

[33] Munteanu I, Bratcu AI, Cutululis N-A, Ceanga E. Optimal control of wind energy systems. London: Springer; 2008.

[34] Miller NW, Price WW, Sanchez-Gasca JJ. Dynamic modeling of GE 1.5 and 3.6 wind turbine-generators. GE Power Syst 2003. 
[35] Hiskens IA. Dynamics of Type-3 wind turbine generator models. IEEE Trans Power Syst 2011;27(1):465-74.

[36] Faiella M, Hennig T, Cutululis NA, Van Hulle F. Capabilities and costs for ancillary services provision by wind power plants. Deliverable D 3.1. Fraunhofer IWES 2013.

[37] Mauricio JM, Marano A, Gómez-Expósito A, Martínez Ramos JL. Frequency regulation contribution through variable-speed wind energy conversion system. IEEE Trans Power Syst 2009;24(1):173-80.

[38] Novaes Menezes EJ, Araújo AM, da Silva NSB. A review on wind turbine control and its associated methods. J Cleaner Prod 2018;174:945-53.
[39] Sebastián R, Peña-Alzola R. Control and simulation of a flywheel energy storage for a wind diesel power system. Electrical Power Energy Syst 2015;64:1049-56.

[40] Takahashi R, Tamura J. Frequency stabilization of small power system with wind farm by using flywheel energy storage system. In: 2007 IEEE international symposium on diagnostics for electric machines, power electronics and drives, Cracow, Poland; 2007.

[41] European Standards EN 50160. Voltage characteristics of electricity supplied by public distribution networks; 2007. 